\title{
Controllable Electrochemical Activities by Oxidative Treatment toward Inner-Sphere Redox Systems at N-Doped Hydrogenated Amorphous Carbon Films
}

\author{
Yoriko Tanaka, ${ }^{1}$ Hiroshi Naragino, ${ }^{1}$ Kohsuke Yoshinaga, ${ }^{1}$ Akira Nakahara, ${ }^{1}$ Takeshi Kondo, ${ }^{2}$ \\ Akira Fujishima, ${ }^{3}$ and Kensuke Honda ${ }^{1}$ \\ ${ }^{1}$ Department of Chemistry and Earth Sciences, Faculty of Science, Yamaguchi University, 1677-1 Yoshida, Yamaguchi-shi, \\ Yamaguchi 753-8512, Japan \\ ${ }^{2}$ Department of Pure and Applied Chemistry, Faculty of Science and Technology, Tokyo University of Science, 2641 Yamazaki, \\ Noda 278-8510, Japan \\ ${ }^{3}$ Kanagawa Academy of Science and Technology (KAST), KSP, 3-2-1, Sakado, Takatsu-ku, Kawasaki city, Kanagawa 213-0012, Japan \\ Correspondence should be addressed to Kensuke Honda, khonda@yamaguchi-u.ac.jp
}

Received 25 April 2011; Revised 18 July 2011; Accepted 19 July 2011

Academic Editor: Giancarlo R. Salazar-Banda

Copyright (C) 2012 Yoriko Tanaka et al. This is an open access article distributed under the Creative Commons Attribution License, which permits unrestricted use, distribution, and reproduction in any medium, provided the original work is properly cited.

The electrochemical activity of the surface of Nitrogen-doped hydrogenated amorphous carbon thin films (a-CNH, N-doped DLC) toward the inner sphere redox species is controllable by modifying the surface termination. At the oxygen plasma treated Ndoped DLC surface (O-DLC), the surface functional groups containing carbon doubly bonded to oxygen $(\mathrm{C}=\mathrm{O})$, which improves adsorption of polar molecules, were generated. By oxidative treatment, the electron-transfer rate for dopamine (DA) positively charged inner-sphere redox analyte could be improved at the N-doped DLC surface. For redox reaction of 2,4-dichlorophenol, which induces an inevitable fouling of the anode surface by forming passivating films, the DLC surfaces exhibited remarkably higher stability and reproducibility of the electrode performance. This is due to the electrochemical decomposition of the passive films without the interference of oxygen evolution by applying higher potential. The N-doped DLC film can offer benefits as the polarizable electrode surface with the higher reactivity and higher stability toward inner-sphere redox species. By making use of these controllable electrochemical reactivity at the O-DLC surface, the selective detection of DA in the mixed solution of DA and uric acid could be achieved.

\section{Introduction}

Boron-doped diamond (BDD) thin film is an ideal polarizable electrode material because it possesses superior electrochemical properties such as a wide working potential range, low background current, and high stability toward electrochemical reaction. The application of BDD as an electrochemical sensor material has been studied intensely in recent years $[1,2]$.

Nitrogen-doped amorphous carbon (a-C:N) has recently attracted attention and been investigated as electrode materials. It has been shown that a-C: $\mathrm{N}$ has a wide potential window and low back current in aqueous media that are comparable with those observed at the BDD electrode
[3-11]. The methods employed for fabricating a-C:N electrodes were a filtered cathodic vacuum arc (FCVA) [3-8], radio-frequency cathodic sputtering from graphite target $[9,10]$, and direct ion beam deposition [11].

As a simple method of nitrogen-doped hydrogenated amorphous carbon thin film (N-doped DLC) synthesis, our research group proposed microwave-assisted plasmaenhanced chemical vapor deposition method using the vapor of nitrogen-containing hydrocarbon as carbon and nitrogen sources [12]. This method is widely used for the diamondlike carbon coating. Our research groups have reported that he N-doped DLC films synthesized using this method had a N/C ratio of 0.08 and contain $s p^{3}$-bonded carbons with atomic ratio $25 / 75 s p^{3} / s p^{2}$. The electrical resistivity and 
optical gap were $0.695 \Omega \mathrm{cm}$ and $0.38 \mathrm{eV}$, respectively [12]. $\mathrm{N}$-doped DLC thin films exhibited a wide working potential range over $3 \mathrm{~V}$, low double-layer capacitance, high resistance to electrochemically induced corrosion in strong acid media, and reversible electron transfer kinetics for inorganic redox analytes $\left(\mathrm{Fe}^{2+/ 3+},\left[\mathrm{Fe}(\mathrm{CN})_{6}\right]^{3-/ 4-}\right.$, and $\left.\mathrm{Ru}\left(\mathrm{NH}_{3}\right)_{6}^{2+/ 3+}\right)$, which were on the same level as those of BDD [12]. Hence, the $\mathrm{N}$-doped DLC films could be an ideal polarizable electrode material with physical stability and chemical inertness, alternative to BDD.

The BDD surface is easily oxidized, and the oxygencontaining functional groups are formed by electrochemical anodization. The charge transfer rates for outer-sphere redox such as ascorbic acid and anthraquinone-2,6-disulfonate (2,6-AQDS) at BDD are significantly altered by the anodic oxidation. Consequently, in the case where BDD is used as the electroanalytical measurements of bio-related compounds (inner-sphere redox species such as dopamine or uric acid), there is a problem that the accuracy of a quantitative analysis might be reduced due to the successive surface oxidation in the long time use.

Since amorphous carbon is composed of a certain amount of $s p^{2}$-bonded carbon atoms, the N-doped DLC electrodes are expected to exhibit the higher reactivity toward inner-sphere redox species same as GC ( $s p^{2}$-bonded carbons). The surface ether group and carboxyl group have been reported to act as adsorption sites for inner-sphere redox species at the electrode surface of $s p^{2}$-bonded carbons (such as GC). On the other hand, amorphous carbon is also composed of $s p^{3}$-bonded carbon atoms, and the $\mathrm{N}$-doped DLC electrodes are expected to show the higher stability toward the electrochemical reaction like that at $\mathrm{BDD}\left(s p^{3}\right.$ bonded carbons).

The objective of this study is to realize an ideal polarizable electrode surface that shows the higher reactivity and higher stability toward inner-sphere redox species (as ascorbic acid). The surface of $\mathrm{N}$-doped DLC was modified with $\mathrm{O}_{2}$ plasma treatment to form ether group and carboxyl group on $s p^{2}$ bonded carbons as a dangling bond and to improve the adsorption properties. Then, the electrochemical reactivity and stability toward inner-sphere redox analyte were investigated.

\section{Experimental}

2.1. Film Growth. The N-doped a-C:H films were prepared using a SAMCO model BP-10 microwave-assisted plasma chemical vapor deposition (CVD) system (SAMCO Co., Ltd.) (the same procedure described in $[12,13])$. Films were deposited on $\mathrm{p}$-Si (111) substrates $\left(5 \times 10^{-3} \Omega \mathrm{cm}\right.$, SUMCO Co., Ltd.) after in situ sputter cleaning with argon ion $(150 \mathrm{~W}$ for 15 minutes). Vapor at a flow rate of $5 \mathrm{~mL} / \mathrm{min}$ was introduced into the evacuated reaction chamber from degassed acetonitrile (carbon and nitrogen source) kept at $50^{\circ} \mathrm{C}$ by heating. The $\mathrm{N}$-doped a-C:H films of $1.5 \mu \mathrm{m}$ thickness were grown by applying RF power $(13.56 \mathrm{MHz})$ on the cathode which held the Si substrates on a quartz liner. The chamber pressure was adjusted at $10 \mathrm{~Pa}$, and the temperature of the stage was set at $176^{\circ} \mathrm{C}$ during deposition. It was possible to fabricate the DLC films with 1.72 (semimetal) $\Omega \mathrm{cm}$ (values were obtained by four-point probe methods) of resistivity could be synthesized by applying $100 \mathrm{~W}$ of RF power. The hardness of resulting $\mathrm{N}$-doped a-C:H films was ca. $9.8 \mathrm{GPa}$ of Martens hardness.

BDD thin films were prepared on a conductive $\mathrm{p}-\mathrm{Si}$ (111) wafer substrate using a microwave plasma-assisted chemical vapor deposition system (ASTeX, Corp., Woburn, Mass, USA). The typical conditions of deposition have been described in the former reports [14].

The oxygen-terminated surfaces of DLC, BDD, and GC were prepared: as-deposited surface (DLC and BDD) or polished surface of GC was treated with plasma etching apparatus (SAMCO Co., Ltd., BP-1) for 1 minute using $\mathrm{O}_{2}$ gas as source gas. The operating pressure of chamber was $20 \mathrm{~Pa}$, and the plasma power was $50 \mathrm{~W}$. The resulting oxygen-plasma-treated surface was used for electrochemical measurements after the pretreatment same as DLC.

2.2. Film Characterization. Raman spectra of the samples were obtained at $531.9 \mathrm{~nm}$ of excitation wavelength using laser Raman spectrophotometer (JASCO RPM-310).

The nitrogen content of films was measured by secondary ion mass spectroscopy (SIMS). The SIMS analysis was performed using a Cameca IMS $4 \mathrm{~F}$ instrument. Films were sputtered with $14.5 \mathrm{kV} \mathrm{Cs}^{+}$ions, and negative secondary ions were monitored. The SIMS concentration of $\mathrm{N}$ in terms of atoms per cubic centimeter was converted to atomic percent by dividing the SIMS concentration values by the overall film atom density.

X-ray photoelectron spectra (XPS) were measured using an XP spectrometer (ESCA Lab MK II, VG Scientific) with a $\mathrm{Mg} \mathrm{K} \mathrm{K}_{\alpha} \mathrm{X}$-ray source. Both survey spectra and highresolution spectra for $\mathrm{C} 1 \mathrm{~s}$ were collected. $\mathrm{C}$ 1s spectra were deconvoluted with software provided with the instrument. The surface morphology of the films was examined with a scanning electron microscope (SEM, JEOL, Model JSM-820).

2.3. Electrochemical Characterization. N-doped DLC thin film deposited on Si substrate (not removed from Si substrate as free-standing $\mathrm{N}$-doped DLC film) was used as a working electrode. Oxide layer was removed from the back of the highly conductive Si substrates with sand paper, and ohmic contact was formed on it. The DLC electrode was rinsed thoroughly and ultrasonicated in isopropanol for 15 minutes. BDD thin films, which were not removed from $\mathrm{Si}$ substrates, were also used as electrodes. The glassy carbon (GC, GC-20; Tokai Co., Ltd.) electrode was polished on a felt pad with alumina powder ( $\alpha$-alumina, $0.5 \mu \mathrm{m}$ ). Then, it was rinsed thoroughly and ultrasonicated in ultrapure water for 5 minutes.

The electrochemical measurements were carried out in a single compartment and three-electrode glass cell with $\mathrm{Ag} / \mathrm{AgCl}$ as a reference electrode and with a $\mathrm{Pt}$ wire as a counter electrode using a digital electrochemical analyzer (Hokuto Denko Co., Ltd., Model HZ-3000). The exposed geometric area of the working electrode was $0.126 \mathrm{~cm}^{2}$. AC impedance measurements were carried out with an 
amplitude of $10 \mathrm{mV}$ in the frequency range from $100 \mathrm{kHz}$ to $0.1 \mathrm{~Hz}$ using a potentiostat/galvanostat and a frequency response analyzer (Solartron, Type 1287 and 1260). Before the measurement, the solutions were bubbled for 15 minutes to remove the dissolved oxygen thoroughly. All the measurements were performed at room temperature $\left(25^{\circ} \mathrm{C}\right)$.

All chemicals were used without further purification. 2,4dichlorophenol (2,4-DCP), 2-propanol, and uric acid were acquired from Wako chemical Co., Ltd. Anthraquinone-2,6disulfonate (2,6-AQDS) and dopamine hydrochloride were acquired from SIGMA. L(+)ascorbic acid was acquired from TCI.

\section{Results and Discussion}

\subsection{Film Composition}

3.1.1. Raman Spectrum, SIMS Analysis, and Electrical Characterization of $N$-Doped DLC Thin Films. To clarify the film composition and the physical properties of the resulting nitrogen-doped DLC films, the characterization by the Raman spectroscopy, secondary ion mass spectroscopy and the Hall measurements were carried out. The Raman spectrum for the N-doped DLC surface shows a pronounced $\mathrm{G}$ peak at $1564 \mathrm{~cm}^{-1}$ and a shoulder around $1357 \mathrm{~cm}^{-1}$ (D peak) that were usually assigned to zone center phonons of $E_{2 g}$ symmetry and $\mathrm{K}$ point phonons of $\mathrm{A}_{1 \mathrm{~g}}$ symmetry, respectively [15-18]. Both scattering peaks, especially D peak, were broad. These broad peaks indicated the disordered (amorphous) structure of the films and no formation of ordered $s p^{2}$ clusters.

Hydrogen content in amorphous carbon films can be estimated from the Raman spectra. As a result of recombination of electron-hole pairs within $s p^{2}$-bonded clusters in hydrogenated amorphous carbon (a-C:H) films, the hydrogen content in films gives rise to a strong photoluminescence (PL) peak. The PL emission peak for a-C:H appears between 1.7 and $2.0 \mathrm{eV}$. When $531.9 \mathrm{~nm}$ is used as excitation wavelength, the first-order Raman modes in amorphous carbon films appear in higher part of the tail in the PL spectrum. PL contributes as linear background to the Raman spectrum. The ratio between the slope $m$ of the fitted linear background and the intensity of $\mathrm{G}$ peak $\left(I_{\mathrm{G}}\right)$, $m / I_{\mathrm{G}}$, can be used as a measure of the bonded $\mathrm{H}$ content in the films. Casiraghi et al. summarized the experimental Raman data of various a-C:H films and have shown that the hydrogen content is related to the normalized PL slope, $m / I_{\mathrm{G}}$, and obtained an empirical relation by means of the fitting of the data points by equation [16]

$$
\mathrm{H}(\text { atom } \%)=21.7+16.6 \log \left(\frac{m}{I_{\mathrm{G}}(\mu \mathrm{m})}\right)
$$

The slope parameter is described in micrometer unit. This method of hydrogen content analysis was carried out for the Raman spectra of N-doped DLC. The slope $m$ and the intensity of $\mathrm{G}$ peak were found to be $932.5 \mu \mathrm{m}$ and 1636.5 , respectively. The $m / I_{\mathrm{G}}$ value $(0.5698 \mu \mathrm{m})$ indicates that 17.6 atom\% of the bonded hydrogen content is included in $\mathrm{N}$ doped DLC films.

Nitrogen contents in the N-doped DLC films were examined using secondary ion mass spectroscopy. The SIMS depth profile showed constant concentration of nitrogen $\left(8.0 \times 10^{21}\right.$ atom $\left.\mathrm{cm}^{-3}\right)$ over entire film thickness $(1.5 \mu \mathrm{m})$. Nitrogen contents of the samples were estimated to be 8.2 atom\% using $1.95 \mathrm{~g} \mathrm{~cm}^{-3}$ of the density of the $\mathrm{N}$-doped DLC films.

At the Hall measurements of the N-doped DLC films grown on Si substrate $(>30 \Omega \mathrm{cm})$ at $25^{\circ} \mathrm{C}$, the Hall coefficient was $-3.63 \mathrm{~cm}^{3} \mathrm{C}^{-1}$. This negative value of $\mathrm{N}$-doped DLC implies n-type conduction, suggesting that nitrogen in the DLC films acts as a donor. Carrier concentration, carrier mobility, and resistivity derived from the results of the Hall measurements were $1.625 \times 10^{18} \mathrm{~cm}^{-3}, 5.38 \mathrm{~cm}^{2} \mathrm{v}^{-1} \mathrm{~s}^{-1}$, and $0.695 \Omega \mathrm{cm}$, respectively.

From the results, it was clarified that N-doped DLC prepared in this study is the hydrogenated amorphous carbon films in which nitrogen atoms were doped up to 8.2 atom $\%$, and these films exhibit n-type conduction by nitrogen doping.

3.1.2. Confirmation of Dopant Atoms and Surface Functionalities on DLC by XPS Measurement. The surfaces of the asdeposited N-doped DLC (AD-DLC) and the oxygen-plasmatreated DLC (O-DLC) that was fabricated to introduce the oxygen-contained functional groups on the DLC surface were evaluated by $\mathrm{X}$-ray photoelectron spectroscopy analysis. The atomic concentration ratio $(\mathrm{O} / \mathrm{C})$ was determined, and the types of surface functional groups were identified. From SEM images of $\mathrm{N}$-doped DLC, BDD, and polished GC surfaces after 1 min oxygen plasma treatment at $50 \mathrm{~W}$ of RF power, no significant morphological change was observed (in SEM images of 60000-fold magnification). It indicated that, by $\mathrm{O}_{2}$ plasma treatment at $50 \mathrm{~W}$ for 1 minute, surface termination can be altered without surface etching (no increase in roughness). Actual areas of N-doped DLC, BDD, and $\mathrm{GC}$ surfaces were not changed by $\mathrm{O}_{2}$ plasma treatment.

In the XPS spectra for AD-DLC and O-DLC at a sweep rate of $10 \mathrm{eV} \mathrm{min}^{-1}$, a sharp C 1s peak was observed at $291 \mathrm{eV}$, and $\mathrm{N}$ 1s and $\mathrm{O}$ 1s peaks were obtained at $400 \mathrm{eV}$ and $538 \mathrm{eV}$, respectively.

The atomic concentration ratio was estimated from the peak area and the sensitivity factors of the atomic assigned. For AD-DLC and O-DLC, the O/C ratios from O 1 s and $\mathrm{C} 1 \mathrm{~s}$ peaks were 0.12 and 0.24 , respectively. The density of oxygencontaining functional groups on the AD-DLC surface was doubled by $\mathrm{O}_{2}$ plasma treatment.

Moreover, to identify the types of oxygen-containing surface functional groups generated on the surfaces of $\mathrm{AD}$ DLC and O-DLC and the ratio of $s p^{3} / s p^{2}$-bonded carbon, the analysis of waveform separation for $\mathrm{C} 1 \mathrm{~s}$ peak obtained at the slow sweep rate of $1 \mathrm{eV} \mathrm{min}^{-1}$ was carried out. The results are shown in Figures 1(c) and 1(d), and the same analysis results of the GC surfaces and the $\mathrm{O}_{2}$ plasma-treated GC (OGC) surface are shown in Figures 1(e) and 1(f). For DLC, the main peak at $290.9 \mathrm{eV}$ after the waveform separation analysis was assigned to the carbon with $s p^{2}$ hybrids in the bulk of 


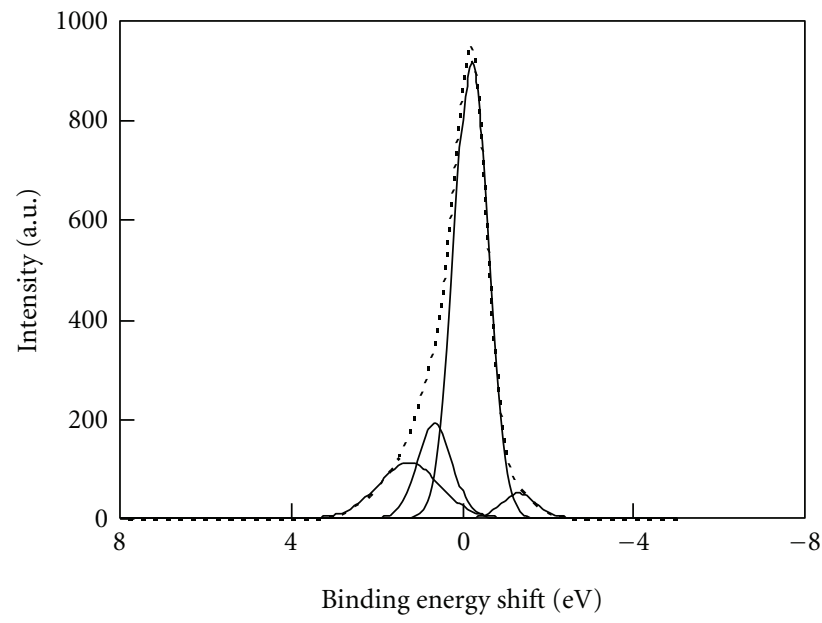

(a) H-BDD

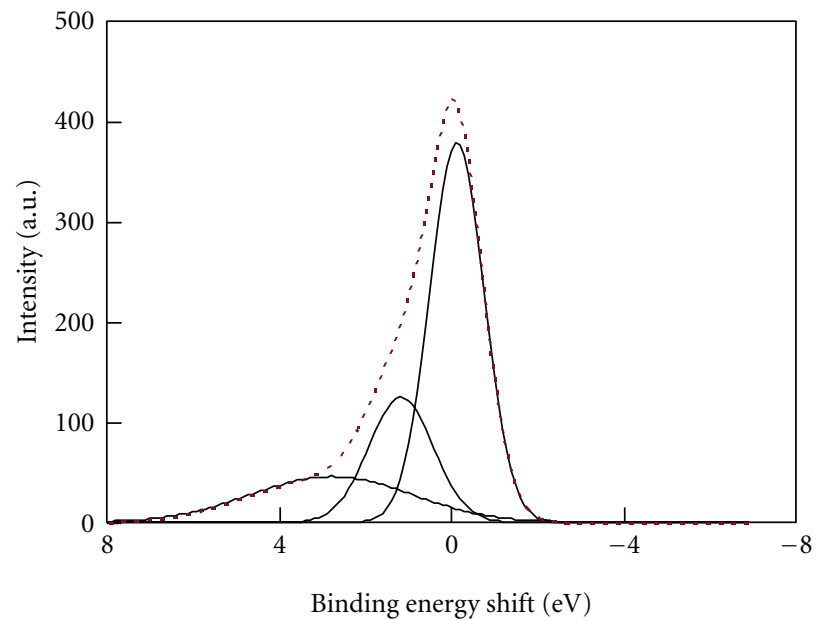

(c) AD-DLC

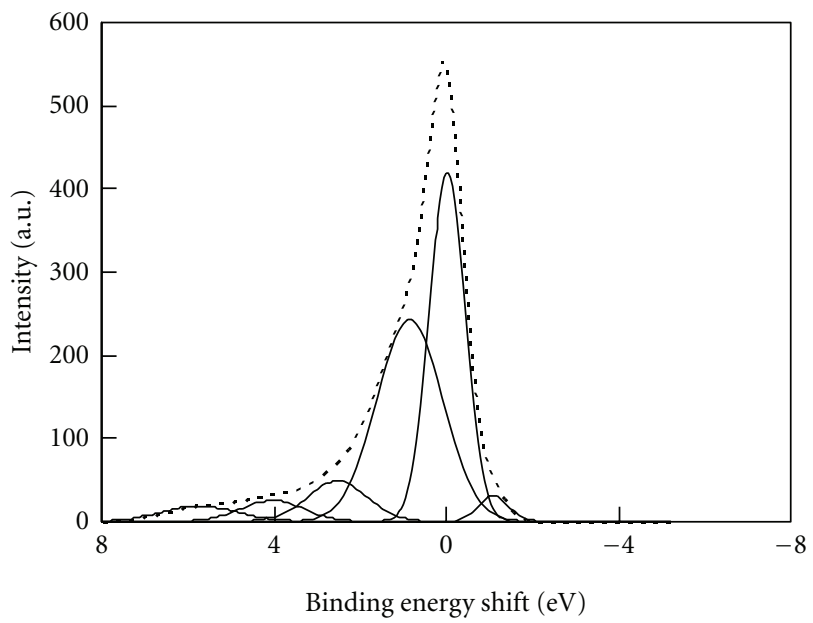

(e) GC

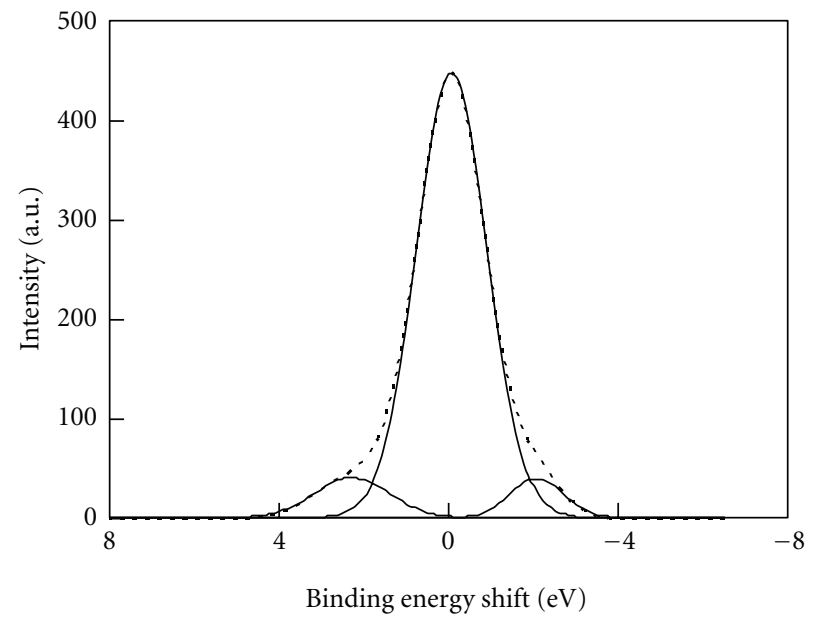

(b) O-BDD

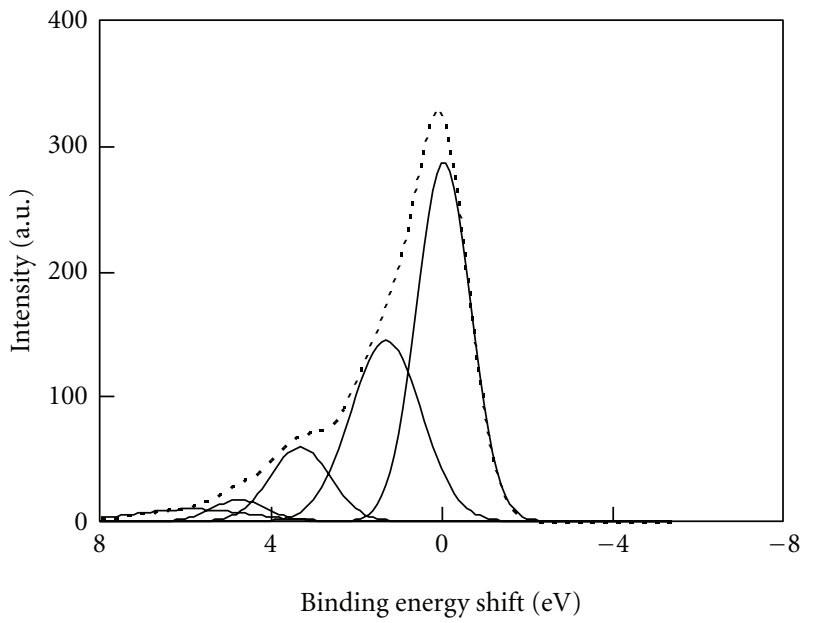

(d) O-DLC

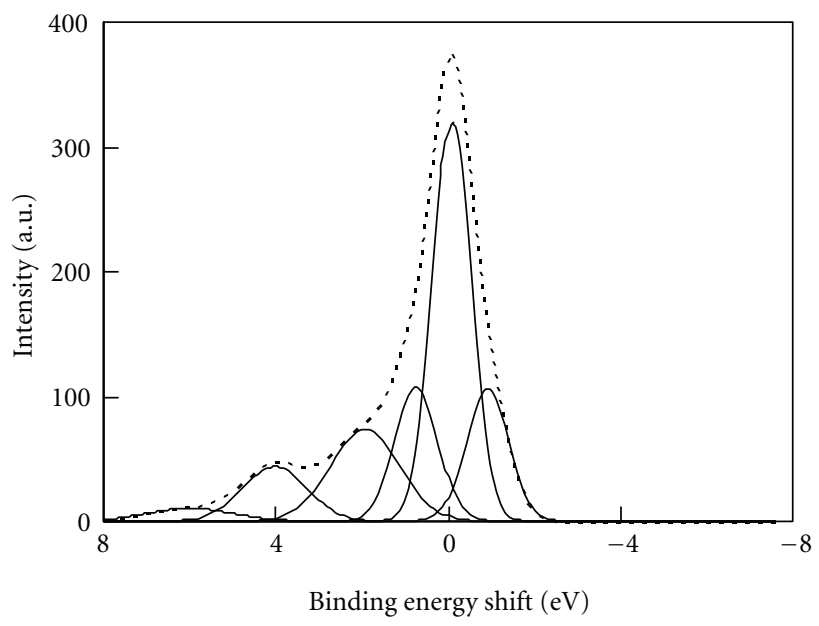

(f) $\mathrm{O}-\mathrm{GC}$

Figure 1: XPS C 1s spectrum for (a) H-BDD, (b) O-BDD, (c) AD-DLC, (d) O-DLC, (e) GC, and (f) O-GC, together with the Lorentzian fit

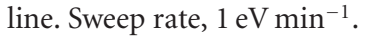


DLC (C1 peak), and it was used as a reference of the binding energy shift (BES).

The other separated peaks for AD-DLC (Figure 1(c)) were the peak of carbon with $s p^{3}$ hybrids in the bulk of DLC (C2 peak) at ca. $+1.3 \mathrm{eV}$ BES, and the peak (C3 peak) assigned to carbon singly bonded to oxygen $(\mathrm{C}-\mathrm{O})$ such as hydroxyl group $(\mathrm{C}-\mathrm{OH})$ and ether structure $(\mathrm{C}-\mathrm{O}-\mathrm{C})$ at ca. $+3.1 \mathrm{eV}$ BES [19]. Relative intensity ratios of these two peaks to the main peak were found to be 0.39 and 0.35 , respectively.

The C 1s peak of O-DLC could be decomposed into five peaks $(\mathrm{C} 1-\mathrm{C} 5)$ as shown in Figure $1(\mathrm{~d})$. In addition to $\mathrm{C} 2$ peak at $+1.4 \mathrm{eV}$ and $\mathrm{C} 3$ peak at $+3.4 \mathrm{eV}$, the peak (C4 peak) assigned to carbon doubly bonded carbon-oxygen $(\mathrm{C}=\mathrm{O})$ such as carboxyl group $(\mathrm{C}-\mathrm{OOH})$ and carbonyl group $(\mathrm{C}=\mathrm{O})$ was observed at $+4.7 \mathrm{eV}$ BES ( $\mathrm{C} 4$ peak), and $\mathrm{C} 5$ peak was obtained at $+5.9 \mathrm{eV}$ BES. Relative intensity ratios of these 4 peaks to the main peak (C1) were found to be 0.66 , $0.23,0.06$, and 0.07 , respectively.

The $s p^{3} / s p^{2}$ ratio, which is the ratio of the peak area of $\mathrm{C} 1$ and C2 peak, is 0.39. N-DLC is a hydrogenated amorphous carbon film that has $28.1 \%$ of the content of $s p^{3}$ hybrids (relative to the $s p^{3}+s p^{2}$ carbons) $\left(71.9 \%\right.$ of $\left.s p^{2}\right) . \mathrm{By}_{2}$ plasma treatment, the density of $\mathrm{C}-\mathrm{O}$ functional groups was decreased to approximately half of that of $\mathrm{AD}-\mathrm{DLC}$, and the formation of $\mathrm{C}=\mathrm{O}$ functional groups was clearly confirmed.

Carbon-oxygen functional groups with double $(\mathrm{C}=\mathrm{O})$ bonding ( $\mathrm{C} 3$ peak) were not present on the as-deposited $\mathrm{BDD}(\mathrm{H}-\mathrm{BDD})$ surface and were not generated by $\mathrm{O}_{2}$ plasma exposure (O-BDD) as shown in Figures 1(a) and 1(b) (the main peak was $s p^{3}$ hybrids in the bulk of BDD; C2 peak).

In the XPS spectra for the polished GC surface (Figure 1(e)), C 1s peak at ca. $289 \mathrm{eV}$ includes the main $\mathrm{C} 1$ peak, $\mathrm{C}-\mathrm{O}$ peak at ca. $+2.6 \mathrm{eV} \mathrm{BES}$, and $\mathrm{C}=\mathrm{O}$ peak at $+4.2 \mathrm{eV}$ BES. The relative intensity ratios of $\mathrm{C}-\mathrm{O}$ and $\mathrm{C}=\mathrm{O}$ to the main peak were found to be 0.1 and 0.07 , respectively. As for the surface of $\mathrm{GC}$ treated by $\mathrm{O}_{2}$ plasma (O-GC), $\mathrm{C} 1$ s peak also includes the same three peaks (Figure 1(f)). Both relative intensity ratios of $\mathrm{C}-\mathrm{O}(0.2)$ and $\mathrm{C}=\mathrm{O}(0.14)$ peaks to $\mathrm{C} 1$ peak were increased by two times to the polished GC surface. The types of surface functionalities on $\mathrm{GC}$ and the trend of the modification by $\mathrm{O}_{2}$ plasma treatment are identical to those on DLC. Hence, on the DLC surface, oxygen-containing surface functional groups including carbon doubly bonded to oxygen $(\mathrm{C}=\mathrm{O})$, which cannot be formed on BDD, can be introduced by $\mathrm{O}_{2}$ plasma treatment.

\subsection{Fundamental Electrochemical Properties of the Conductive} DLC Electrode Potential Window, Electrochemical Double Layer Capacitance. The fundamental electrochemical properties of the N-doped DLC films that have been reported in a previous publication [12] are summarized as follows. The N-doped DLC films exhibited a wide working potential range over $3 \mathrm{~V}$, which is on the same level as that of BDD. The working potential windows $\Delta E\left(=E_{\mathrm{ox}}-E_{\mathrm{red}}\right)$ in $0.1 \mathrm{M}$ $\mathrm{Na}_{2} \mathrm{SO}_{4}$ for N-doped DLC and BDD were observed to be 2.97 and 2.62 , respectively. These results indicate that $\mathrm{N}$ doped DLC exhibits the lower reactivity toward hydrogen and oxygen evolution. It was caused by fewer adsorption sites than noble metal, which are needed for hydrogen and oxygen evolution (slightly higher than those of BDD), and by the potential drop within the electrode due to the lower carrier density [12]. A wide working potential range in aqueous media indicates that $\mathrm{N}$-doped DLC has ideal polarizable properties, which are close to BDD [20].

The N-doped DLC films exhibited a lower double-layer capacitance, which is also on the same level as that of BDD [12]. In the potential range from $-0.5 \mathrm{~V}$ to $1 \mathrm{~V}$, double layer capacitance for $\mathrm{N}$-doped DLC estimated from AC impedance measurements were from $8 \mu \mathrm{F} \mathrm{cm}^{-2}$ to $20 \mu \mathrm{F} \mathrm{cm}^{-2}$ (obtained from the data at $10 \mathrm{~Hz}$ ). The values were low and were comparable in magnitude to the values observed for BDD $\left(8 \sim 17 \mu \mathrm{F} \mathrm{cm}^{-2}\right)$ and HOPG $\left(6 \sim 23 \mu \mathrm{F} \mathrm{cm}^{-2}\right)$ at the same frequency; on the other hand, they were approximately half of those for GC $\left(24 \sim 37 \mu \mathrm{F} \mathrm{cm}^{-2}\right)$.

\subsection{Electrochemical Activity of N-Doped DLC Electrode} Surface. The electrochemical responses of the N-doped DLC surface were evaluated by the electron-transfer kinetics of various inner and outer-sphere redox species. At the BDD electrodes, the electron-transfer rate has been reported to be seriously affected by the substitution of the surface terminated atoms from hydrogen to the oxygen-containing functional groups by anodic oxidation or exposure to $\mathrm{O}_{2}$ plasma [21]. On the other hand, the surface of as-deposited DLC possesses some of the oxygen-containing functional groups by the reaction with $\mathrm{O}_{2}$ in the air just after CVD deposition as already shown in XPS results. It is expected that, unlike BDD, the electrochemical response of $\mathrm{N}$-doped DLC is not significantly changed by surface oxidation in the long-term electrochemical use. In this section, the $\mathrm{N}$-doped DLC surface was prepared by the exposure to $\mathrm{O}_{2}$ plasma, and the electrochemical reactivity at the oxidized surface $(\mathrm{O}-$ DLC) was compared with that at the as-deposited $\mathrm{N}$-doped DLC surface (AD-DLC); then, the difference of reactivity between DLC and BDD was verified.

3.3.1. Charge Transfer Kinetics of Outer-Sphere Redox Species. The reactivity toward one-electron outer-sphere redox species, $\mathrm{Ru}\left(\mathrm{NH}_{3}\right)_{6}^{3+/ 2+}, \mathrm{Fe}^{3+/ 2+}$, and $\mathrm{Fe}(\mathrm{CN})_{6}^{3-/ 4-}$, have been examined using cyclic voltammetry in a previous report [12]. The results are roughly summarized as follows.

In cyclic voltammograms $(\mathrm{CV})$ for $\mathrm{Ru}\left(\mathrm{NH}_{3}\right)_{6}^{3+/ 2+}$ at $10 \mathrm{mV} \mathrm{s}^{-1}$ of sweep rate, the values of peak separation $\Delta E_{\mathrm{p}}$ at AD-DLC and O-DLC were $124 \mathrm{mV}$ and $97 \mathrm{mV}$, respectively, indicating nearly the reversible response. The heterogeneous electron transfer rate constants, $k_{0}$, were $2.66 \times 10^{-3} \mathrm{~cm} \mathrm{~s}^{-1}$ and $2.95 \times 10^{-3} \mathrm{~cm} \mathrm{~s}^{-1}$ obtained from AC impedance measurements [12]. The values of $k_{0}$ for $\mathrm{Ru}\left(\mathrm{NH}_{3}\right)_{6}^{3+/ 2+}$ at $\mathrm{N}$-doped DLC were unaffected by surface oxidation and were insensitive to the surface microstructure. This tendency was same as BDD.

On the other hand, at N-doped DLC, the values of $\Delta E_{\mathrm{p}}$ in CVs for $\mathrm{Fe}^{3+/ 2+}\left(10 \mathrm{mV} \mathrm{s}^{-1}\right)$ at AD-DLC was $737 \mathrm{mV}$ that was consistent with $k_{0}, 1.02 \times 10^{-5} \mathrm{~cm} \mathrm{~s}^{-1}$ [12]. $\Delta E_{\mathrm{p}}$ at O-DLC was $274 \mathrm{mV}$ and decreased by $460 \mathrm{mV}$ after surface oxidation. The value of $k_{0}$ increased by a factor of three to $2.72 \times 10^{-5} \mathrm{~cm} \mathrm{~s}^{-1}$, and the electron transfer was 


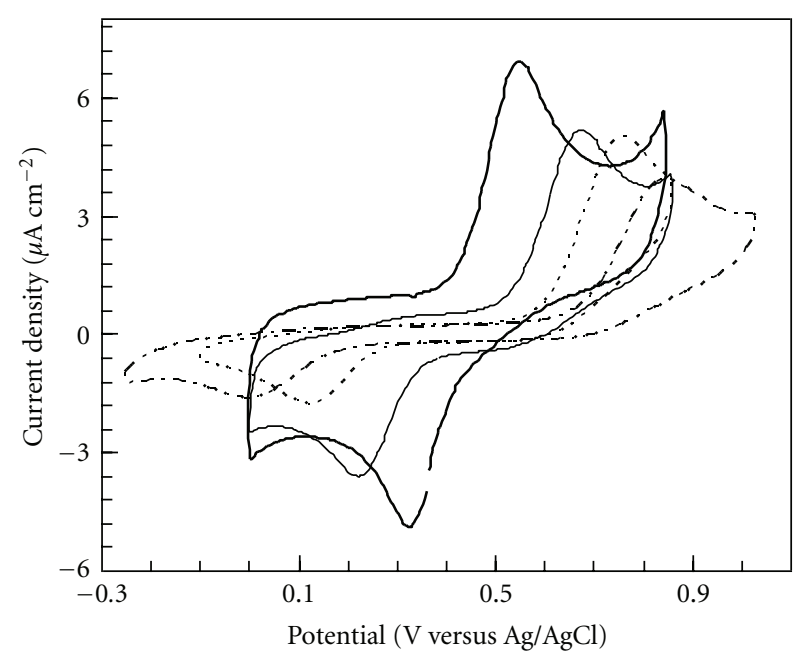

Figure 2: Cyclic voltammograms of $20 \mu \mathrm{M}$ dopamine hydrochloride in $0.1 \mathrm{M} \mathrm{HClO}_{4}$ at AD-DLC (thin solid line), O-DLC (thick solid line), H-BDD (dotted line), and O-BDD (dashed-dotted line). Sweep rate, $20 \mathrm{mV} \mathrm{sec}^{-1}$.

accelerated by $\mathrm{O}_{2}$ plasma treatment [12]. This tendency was consistent with $\mathrm{BDD}$. These results indicate that the oxygencontainING functional groups formed on $\mathrm{N}$-doped DLC may mediate the electron transfer of this redox system or that the force of electrostatic attraction for redox ions with positive charges was caused by the surface dipole of the oxygen-containING functional groups.

Consequently, for one-electron outer-sphere redox species with positive charge such as $\mathrm{Fe}^{3+/ 2+}$ and $\mathrm{Ru}\left(\mathrm{NH}_{3}\right)^{3+/ 2+}$, the electrochemical response and the tendency of the change of the kinetics at N-doped DLC by surface oxidation were very close to those at $\mathrm{BDD}$.

It of has been reported that the electron-transfer rate $\mathrm{Fe}(\mathrm{CN})_{6}^{3-/ 4-}$ with negative charge at graphite electrodes is not dependent on the amount of surface oxygen but the amount of exposed edge plane on $s p^{2}$-bonded carbon [22, $23]$, and $\Delta E_{\mathrm{p}}$ was decreased by electrochemical (oxidative) pretreatment at GC [21]. On the BDD surface, the electrontransfer kinetics was decreased $\left(\Delta E_{\mathrm{p}}\right.$ was increased) by oxygen plasma treatment due to the electrostatic repulsive force between surface dipole on O-BDD and charges on $\mathrm{Fe}(\mathrm{CN})_{6}^{3-14-}[21]$. At the N-doped DLC electrodes, the value of $\Delta E_{\mathrm{p}}$ was approximately constant (ca. $250 \mathrm{mV}$ ) before and after surface oxidation. The $k_{0}$ values were estimated to be 1.02 and $0.32 \times 10^{-4} \mathrm{~cm} \cdot \mathrm{s}^{-1}$ at AD-DLC and O-DLC, respectively [12].

On the surface of DLC, approximately $3 / 4$ of surface carbons are $s p^{2}$ hybrids and $1 / 4$ of surface carbons are $s p^{3}$ hybrids. The carbon-oxygen functionalities on $s p^{3}$-bonded carbons introduced by oxygen plasma treatment can exhibit the repulsive force for $\mathrm{Fe}(\mathrm{CN})_{6}^{3-/ 4-}$ similar to BDD. $\mathrm{O}_{2}$ plasma treatment may increase surface roughness and the exposed $s p^{2}$-bonded carbons leading to the enhancement of the reactivity toward $\mathrm{Fe}(\mathrm{CN})_{6}^{3-/ 4-}$. Owing to these countervailing effects, it can be supposed that $\Delta E_{\mathrm{p}}$ showed the constant values for AD-DLC and O-DLC, and the change of reactivity toward $\mathrm{Fe}(\mathrm{CN})_{6}^{3-/ 4-}$ by surface oxidation may be different from that for BDD.

3.3.2. Evaluation of Electrochemical Response Using InnerSphere Redox Species with Positive Charge. N-doped DLC that contains $s p^{2}$-bonded carbons is supposed to have more physical and chemical adsorption sites compared with BDD. The characterization of the N-doped DLC surfaces was studied using the redox systems of which kinetics strongly correlate with the adsorption of the analytes on the electrode surface. First of all, the reactivity toward dopamine (DA) was examined. DA is electrochemically oxidized and changed to 4-(2-amino-ethyl)-[1,2]benzoquinone and exhibit reversible behavior. DA is protonated in acidic media and positively charged in amino group. It has been reported that the kinetics of DA is highly dependent on the surface adsorption [22]. However, at the BDD surface, the kinetics $\left(\Delta E_{\mathrm{p}}\right)$ is not changed $\left(\Delta E_{\mathrm{p}}\right.$ was slightly increased) by surface oxidation due to a lack of adsorption sites on both as-deposited and oxygen-terminated BDD surfaces [24]. The surface carbonoxygen functionalities formed on BDD are not influential. Figure 2 shows the cyclic voltammograms of $20 \mu \mathrm{M}$ DA at the BDD and the N-doped DLC surfaces. The value of $\Delta E_{\mathrm{p}}$ at $\mathrm{H}-\mathrm{BDD}$ was found to be $656 \mathrm{mV}$; this relatively large $\Delta E_{\mathrm{p}}$ indicates that DA exhibits electrochemical irreversibility. As the formal potential of DA is higher than that of $\mathrm{Fe}(\mathrm{CN})_{6}^{3-14-}$ (that shows quasireversible behavior as shown in [12]), a low density of electronic state is not a cause of the larger $\Delta E_{\mathrm{p}}$. However, a lack of adsorption on BDD can be one of the causes of slow kinetics. By the oxidative treatment of the $\mathrm{BDD}$ surface, $\Delta E_{\mathrm{p}}$ was slightly increased to $856 \mathrm{mV}$, and the potential of oxidation peak was positively shifted by $90 \mathrm{mV}$.

Interestingly, at the $\mathrm{N}$-doped DLC surface, the $\Delta E_{\mathrm{p}}$ value was decreased from $478 \mathrm{mV}$ to $241 \mathrm{mV}$ by oxygen plasma treatment. The potential of the oxidation peak was negatively shifted by $120 \mathrm{mV}$. The similar behavior of $\Delta E_{\mathrm{p}}$ toward oxidative treatment was observed at GC that was composed of $s p^{2}$-bonded carbons $\left(\Delta E_{\mathrm{p}}\right.$ was decreased from $295 \mathrm{mV}$ to $42 \mathrm{mV}$, and the oxidation peak was negatively shifted by $120 \mathrm{mV}$ ). It has been reported that, at GC, $\Delta E_{\mathrm{p}}$ is in the range of $125-175 \mathrm{mV}$ [25], and the $\Delta E_{\mathrm{p}}$ of DA is dependent on the surface microstructure, the amount of surface oxygen, and the $s p^{2}$ bonds carbon on the surface. The $\pi-\pi$ interaction between the $s p^{2}$ bonds of the surface and polar aromatic DA may play an important role for $\Delta E_{\mathrm{p}}[22,26]$.

Considering that $\Delta E_{\mathrm{p}}$ value at AD-DLC was lower by a factor of 0.7 than that at H-BDD (faster electrontransfer kinetics) and the trend of the change in $\Delta E_{\mathrm{p}}$ at $\mathrm{N}$-doped DLC and GC by surface oxidation was opposite to that at $\mathrm{BDD}$, it is conceivable that the specific oxygencontaining functionalities which can be generated only at $s p^{2}$-bonded carbons (not generated at BDD) such as carbonyl and carboxyl groups may strongly affect the kinetics of DA. These functional groups are thought to enhance adsorption of inner-sphere redox species. In order to clarify the relation between the rates and the adsorption of DA at $\mathrm{N}$-doped DLC and BDD, the quantitative determination of the surface coverage of dopamine on each electrode surface was examined. The electrolysis charge at $\mathrm{N}$-doped 
TABLE 1: Dopamine adsorption data for all six carbon electrodes.

\begin{tabular}{lc}
\hline Electrode & $\begin{array}{c}\text { Amount of surface coverage } \\
\left(\mathrm{pmol} \mathrm{cm}^{-2}\right)\end{array}$ \\
\hline O-GC & 221 \\
O-DLC & 221 \\
AD-DLC & 163 \\
GC & 130 \\
H-BDD & 125 \\
O-BDD & 105 \\
\hline
\end{tabular}

DLC was evaluated with the double-step chronocoulometric measurements for $20 \mu \mathrm{M} \mathrm{DA}$ in $0.1 \mathrm{M} \mathrm{HClO}_{4}$ using 5-s potential steps from $740 \mathrm{mV}$ to $170 \mathrm{mV}$ in the presence and absence of DA. The total electrolysis charge is given by the following equation. It contains the double-layer charge $Q_{\mathrm{dl}}$, the charge for adsorbed analyte $Q_{\text {ads }}$, and the faradic charge for the diffusion-controlled electrolysis $Q_{\text {faradic }}$

$$
\begin{aligned}
Q_{\text {total }} & =Q_{\text {faradic }}+Q_{\mathrm{dl}}+Q_{\mathrm{ads}} \\
& =\frac{2 n F A D^{1 / 2} C t^{1 / 2}}{\pi^{1 / 2}}+Q_{\mathrm{dl}}+n F A \Gamma,
\end{aligned}
$$

where $A$ represents the electrode area $\left(\mathrm{cm}^{2}\right), D$ represents the diffusion coefficient $\left(\mathrm{cm}^{2} \mathrm{~s}^{-1}\right), C$ represents the concentration $\left(\mathrm{pmol} \mathrm{cm}^{-3}\right)$, and $\Gamma$ represents the surface coverage of adsorbate $\left(\mathrm{pmol} \mathrm{cm}{ }^{-2}\right)$ [24]. The background-corrected charge was plotted against $t^{1 / 2}$ and, from the charge axis intercept, the surface coverage of adsorbate $(n F A \Gamma)$ was estimated. In Table 1, the chronocoulometric charge data for dopamine electrolysis at N-doped DLC, BDD, and GC before and after surface oxidation are summarized. The charge data have been converted into units of pmol cm${ }^{-2}$ using Faraday's law. On the BDD surface, the surface coverage $(\Gamma)$ of DA was slightly decreased from 125 (H-BDD) to 105 (O-BDD) pmol cm${ }^{-2}$ by oxygen plasma treatment. On the other hand, $\Gamma$ at $\mathrm{N}$-doped DLC was increased by a factor of 1.4 after surface oxidation (163 and $221 \mathrm{pmol} \mathrm{cm}^{-2}$ at AD-DLC and O-DLC, resp.). The value of $\Gamma$ at GC was also increased from $130 \mathrm{pmol} \mathrm{cm}$-2 to $221 \mathrm{pmol} \mathrm{cm}{ }^{-2}$ as in the case of DLC. The trend of $\Gamma$ for surface oxidation was consistent with the behavior of $\Delta E_{\mathrm{p}}$ toward surface oxidation. At the $\mathrm{N}$ doped DLC and GC surfaces which show higher $\Gamma$ value of DA after surface oxidation, the electron-transfer kinetics was improved. However, at the BDD surface, the rate for dopamine was slightly decreased, and $\Gamma$ was decreased by surface oxidation.

As shown in Section 3.1.2, at both BDD and N-doped DLC, O/C ratios were increased by oxygen plasma treatment. The $\Gamma$ value of DA, therefore, is supposed to be related not to the amount of surface oxygen but to the types of oxygencontaining surface groups generated on the oxidized surface. From the result of XPS measurement, only the carbons singly bonded to oxygen $(\mathrm{C}-\mathrm{O})$ could be formed on $\mathrm{BDD}$, whereas the carbons doubly bonded to oxygen $(\mathrm{C}=\mathrm{O})$ were generated after surface oxidation at $\mathrm{N}$-doped DLC and GC. Hence, it was thought that the $\mathrm{C}=\mathrm{O}$ functional groups significantly

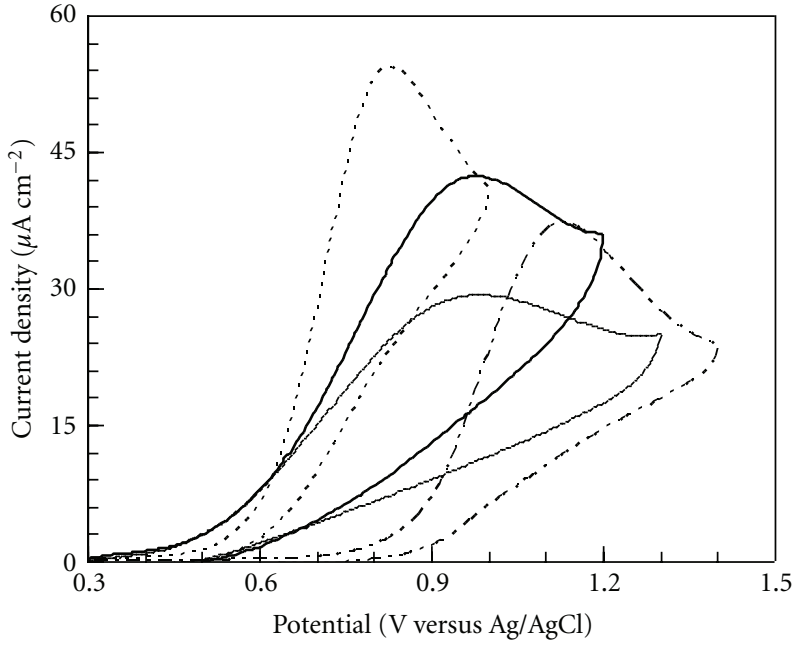

FIgure 3: Cyclic voltammograms of $0.5 \mathrm{mM}$ ascorbic acid in $0.1 \mathrm{M}$ $\mathrm{HClO}_{4}$ at AD-DLC (thin solid line), O-DLC (thick solid line), HBDD (dotted line), and O-BDD (dashed-dotted line). Sweep rate, $20 \mathrm{mV} \mathrm{s}^{-1}$.

contribute to the increase in the amount of adsorption of analytes, which results in the improvement of the electrontransfer kinetics. It is summarized that, for the positively charged inner-sphere redox species like dopamine, at the DLC surface, the electron-transfer rate can be improved by oxidative treatment to a higher value than at $\mathrm{H}-\mathrm{BDD}$ and $\mathrm{O}-\mathrm{BDD}$. This is because the adsorption of redox species can be enhanced in addition to the effect of the electrostatic interaction (attractive force) between the surface dipoles and the charge on the redox analytes.

\subsubsection{Evaluation of Electrochemical Response Using Inner-} Sphere Redox Species with a Large Dipole or Negative Charge. Among the inner-sphere redox species, the electrochemical reactivity toward ascorbic acid (AA) was examined at the Ndoped DLC surface. The reactivity of AA has been reported to vary significantly after oxidative surface treatment [27]. AA is electrochemically oxidized and changed to dehydroascorbic acid at the electrode surface. (This oxidation is chemically irreversible.) At the BDD surface, the oxidation peak potential $\left(E_{\mathrm{p}}{ }^{\mathrm{ox}}\right)$ for $\mathrm{AA}$, which is electrically neutral molecule, was positively shifted by $0.27 \mathrm{~V}$ in acidic solution by surface oxidation (Figure 3) [27]. This decrease in the rate for AA oxidation is because the most stable distance between AA and the electrode surface extends with the change of the terminated atoms from hydrogen- to oxygen-containing surface groups (from $4.9 \AA$ to $6.8 \AA$ ) due to the decrease in the interaction energy between AA (6.42 Debyes) and surface dipoles [28]. It results in the lower charge-transfer kinetics. On the other hand, at the GC surface, it has been known that $E_{\mathrm{p}}{ }^{\text {ox }}$ for AA exhibits the constant value for the oxidative surface treatment and indicates the stable electrochemical response to surface oxidation [28].

In the cyclic voltammograms of $0.5 \mathrm{mM}$ ascorbic acid (Figure 3), the value of $E_{\mathrm{p}}{ }^{\text {ox }}$ at N-doped DLC was observed at $0.98 \mathrm{~V}$ and was constant before and after surface oxidation. 


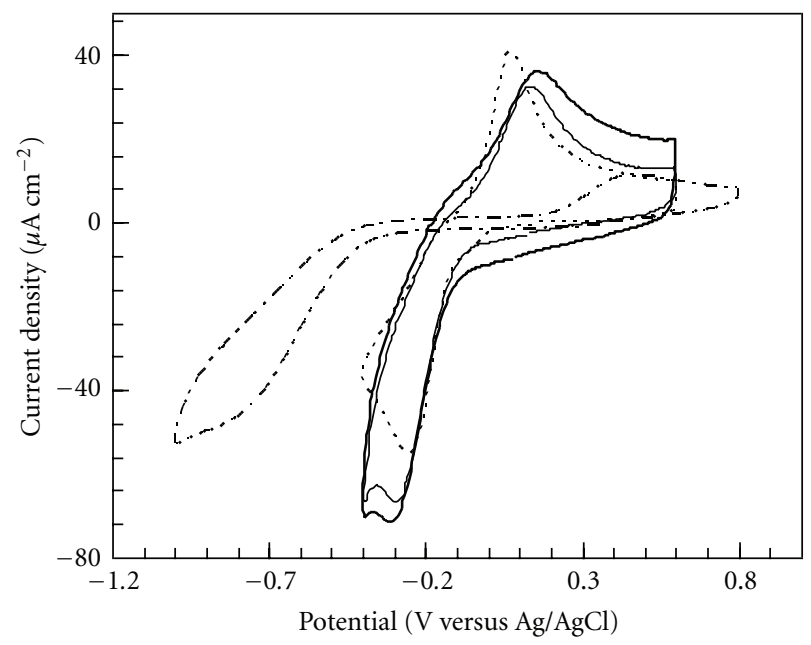

(a)

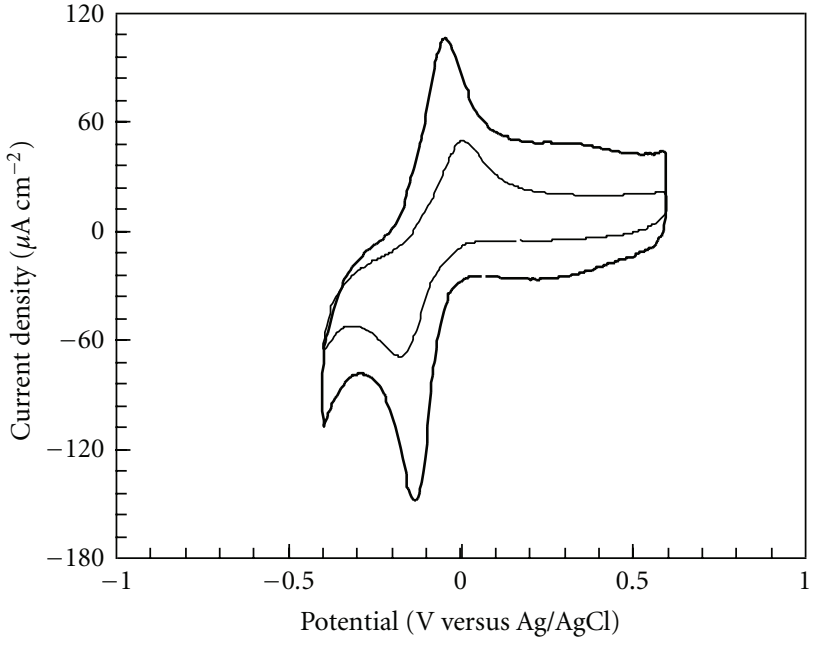

(b)

FIgure 4: Cyclic voltammograms of $100 \mu \mathrm{M}$ 2,6-AQDS in $0.1 \mathrm{M} \mathrm{HClO}_{4}$ (a) at AD-DLC (thin solid line), O-DLC (thick solid line), H-BDD (dotted line), and O-BDD (dashed-dotted line), (b) GC (thin solid line) and O-GC (thick solid line). Sweep rate, $20 \mathrm{mV} \mathrm{s}^{-1}$.

Only the current density at the peak potential was increased by $1.3 \mu \mathrm{A}$. On the O-DLC surface, the surface dipoles are thought to exhibit the weak interaction energy (repulsive force) for $\mathrm{AA}$, as is the case of the O-BDD surface. On the other hand, the amount of adsorption is considered to be simultaneously improved by the increase of the $\mathrm{C}=\mathrm{O}$ functional groups (adsorption sites). Owing to these countervailing effects, the stable distance of AA from the DLC surface was not changed even after surface oxidation, and the $E_{\mathrm{p}}{ }^{\mathrm{ox}}$ showed the constant values for AD-DLC and ODLC. In other words, the reactivity of N-doped DLC toward inner-sphere redox species with a large dipole like AA is more stable than that at BDD. It indicates that N-doped DLC is a superior electrode material in electroanalytical assays for electroactive compounds.

The analysis of inner-sphere redox species with negative charge in relation to the electrochemical response and the surface coverage was performed using anthraquinone-2,6disulfonate (2,6-AQDS), which is polar molecule. 2,6-AQDS undergoes a reversible two-proton and two-electron redox reaction. The oxidized and reduced forms of 2,6-AQDS strongly physisorb on the polar electrode surfaces such as GC by dipole-dipole and ion-dipole interactions although 2,6AQDS weekly physisorbs on the nonpolar electrode surfaces such as hydrogen-terminated BDD surface [24].

Figure 4 shows cyclic voltammograms of $100 \mu \mathrm{M} 2,6$ AQDS at AD-DLC, O-DLC, H-BDD, and O-BDD. Table 2 summarizes the charge data for 2,6-AQDS electrolysis (the values were converted to the surface coverage) that were obtained using the same method employed for the $\Gamma$ values of dopamine. In Figure $4(\mathrm{a})$, at BDD, the $\Delta E_{\mathrm{p}}$ value was increased from $3542 \mathrm{mV}$ to $1243 \mathrm{mV}$ by oxygen plasma treatment, which indicated that charge-transfer rate was significantly decreased with the increase in the amount of oxygen-containing surface functional groups. The $\Delta E_{\mathrm{p}}$ for GC and O-GC were 209 and $120 \mathrm{mV}$, respectively;
TABLE 2: 2,6-AQDS adsorption data for all six carbon electrodes.

\begin{tabular}{lc}
\hline Electrode & $\begin{array}{c}\text { Amount of surface coverage } \\
\left(\mathrm{pmol} \mathrm{cm}^{-2}\right)\end{array}$ \\
\hline O-GC & 128 \\
GC & 14.0 \\
AD-DLC & 10.9 \\
H-BDD & 4.72 \\
O-DLC & 2.60 \\
O-BDD & 2.54 \\
\hline
\end{tabular}

the value was slightly decreased after surface oxidation (Figure 4(b)). The peak current density was increased by a factor of two (from $49 \mu \mathrm{A} \mathrm{cm}^{-2}$ to $100 \mu \mathrm{A} \mathrm{cm}^{-2}$ ). The values of $\Delta E_{\mathrm{p}}$ at AD-DLC and O-DLC were found to be 440 and $478 \mathrm{mV}$, respectively (Figure $4(\mathrm{a})$ ). The charge-transfer rate for 2,6-AQDS was not varied by oxygen plasma treatment. Therefore, it was clarified that the reactivity toward 2,6AQDS at N-doped DLC was intermediate between those on the $\mathrm{BDD}$ and on the GC surface. At GC, both the decrease of $\Delta E_{\mathrm{p}}$ and the increase of peak current density by surface oxidative treatment may be attributable to the increase in the amount of surface coverage of 2,6-AQDS. The $\Gamma$ value at GC was increased 9-fold from $14.0 \mathrm{pmol} \mathrm{cm}^{-2}$ to $128 \mathrm{pmol} \mathrm{cm}^{-2}$ as shown in Table 2. On the other hand, at the O-DLC surface, the amount of surface coverage of 2,6AQDS was $2.6 \mathrm{pmol} \mathrm{cm}^{-2}$, which was close to those at the $\mathrm{H}-\mathrm{BDD}$ and O-BDD electrodes. This value was relatively lower than that at the as-deposited DLC surface. Hence, at the O-DLC surface, the contribution of the electrostatic repulsive force for the redox species with negative charge (2,6-AQDS) is higher than the increase of the adsorption sites with large surface dipole like $\mathrm{C}=\mathrm{O}$ groups. As a result, the surface coverage was decreased and the electron-transfer rate 
was not improved. At N-doped DLC, it is apparent that the degradation of the electrochemical response for 2,6-AQDS (increase of $\Delta E_{\mathrm{p}}$ ) in long time use may not occur.

\subsubsection{The Durability of the N-Doped DLC Electrodes for Inner-} Sphere Redox Species. It is well known that, at the $s p^{2}$ bonded carbon electrodes such as GC, the molecules with larger polarity or charge strongly adsorb and the surface fouling occurs due to the buildup of adsorbtion reaction products. This surface fouling causes a problem of low stability of the electrode performance in the electroanalytical application. At the DLC surface where the specific innersphere species highly adsorb, there is apprehension that the electroanalytical performance is degraded in a prolonged use. Therefore, the stability of the electrochemical performance at the DLC surface before and after oxidative treatment was studied using 2,4-dichlorophenol (2,4-DCP). 2,4-DCP generates passive film by the oxidation at solid electrode, which has strong and continuous adhesion to the electrode surface, resulting in the fouling of the electrode surface [29]. The anodic reaction proceeds through an initial one-electron step to form phenoxy radicals, which subsequently can undergo either polymerization or further oxidation with transfer of oxygen from hydroxyl radicals at the electrode surface to produce $o$-benzoquinone or $p$ benzoquinone. Chlorinated benzoquinone is assumed to be the main oxidation product. The same evaluation was carried out at BDD and GC. First, for low concentration $(0.1 \mathrm{mM})$ of 2,4-DCP in the Britton-Robinson buffer ( $\mathrm{pH}$ 2), potential cycling tests were carried out in the potential range from $-0.7 \mathrm{~V}$ to $1.7 \mathrm{~V}$ at O-DLC and at O-BDD, from $-0.7 \mathrm{~V}$ to $1.3 \mathrm{~V}$ at $\mathrm{H}-\mathrm{BDD}$, and from $-0.4 \mathrm{~V}$ to $1.1 \mathrm{~V}$ at $\mathrm{GC}$, respectively. The CVs for $0.1 \mathrm{mM}$ 2,4-DCP were shown in Figure 5. In $\mathrm{CV}$, the anodic peaks were obtained at approximately $1.1 \mathrm{~V}$ versus $\mathrm{Ag} / \mathrm{AgCl}$ at $\mathrm{AD}-\mathrm{DLC}$ and O-DLC. The anodic peaks at polished GC and H-BDD were less positive than those of DLC and were found at $0.94 \mathrm{~V}$ and $1.05 \mathrm{~V}$, respectively. The shift of the peak potential (from that at GC) was largest at O-BDD $(1.44 \mathrm{~V})$. The oxidation peak potential of 2,4DCP was sensitive to surface microstructure of the electrode. The oxygen-containing functional groups (especially $\mathrm{C}-\mathrm{O}$ groups formed on $s p^{3}$-bonded carbons) strongly affect the peak potential shift of 2,4-DCP oxidation. The feature of CV was consistent with that at $\mathrm{O}-\mathrm{BDD}$ reported in the previous publication [29]. The current densities at the oxidation peak during the potential cycling were shown in Figure 6. The peak currents in $\mathrm{CV}$ for $0.1 \mathrm{mM} 2,4-\mathrm{DCP}$ at $\mathrm{AD}$ DLC and O-DLC were linearly proportional to sweep rate $\left(v^{1 / 2}\right)$ in the range of $10-500 \mathrm{mV} \mathrm{s}^{-1}$. It indicates that the oxidation current is diffusion controlled. In Figure 6, the peak current densities were decreased to approximately half and 0.7 of the initial value at GC and at H-BDD after 30 cycles, respectively. At GC and H-BDD, the electrode surface was oxidized (or oxygen-terminated) or corroded by applying higher potential in aqueous solution. To prevent surface oxidation, the upper potential limit was set at $1.3 \mathrm{~V}$ and $1.1 \mathrm{~V}$, at $\mathrm{H}-\mathrm{BDD}$ and GC, respectively. The oxidation of phenol derivatives forms passivating polymeric films on the electrode surface, resulting in the inevitable fouling at
GC and H-BDD. In addition, the surface-adsorbed reaction products also have been considered to cause the degradation of electrode performance [29]. After the potential cycling, the surface morphologies of the H-BDD and the GC electrodes were observed by the optical microscope. It was confirmed that small clumps of polymeric films were inhomogeneously distributed on both electrode surfaces.

On the other hand, the peak current at O-DLC at which inner-sphere redox analytes highly adsorb was slightly increased with cycle numbers (by ca. $10 \%$ of the initial value at 100 cycles) and reached a constant value at 50 cycles; the trend was same as that at AD-DLC. As a result, it was clarified that the response of 2,4-DCP oxidation at O-DLC was not varied by long-term potential cycling, and the durability of 2,4-DCP oxidation reaction was remarkably high. This higher durability is mainly due to the following: the passive films (the same films formed on GC and H-BDD) could be decomposed by applying higher potential (at over $1.7 \mathrm{~V}$ ) at O-DLC. Moreover, the adsorption of this decomposed products and phenol derivatives on the O-DLC surface is considered to be very low because of the repulsive force from the negative surface dipolar field formed on the ODLC surface, as is the case of O-BDD [29]. Therefore, for 2,4-DCP oxidation, the surface fouling did not occur on the DLC surface. These explanations are supported by the fact that the polymeric films cannot be observed by the optical microscope at the O-DLC and O-BDD surfaces after the potential cycling.

The fouling of the electrode is enhanced at higher concentrations (2,4-DCP) [29]. The durability of the performance of the DLC electrodes at high concentration, $5 \mathrm{mM}$ 2,4-DCP, was examined using long-term potential cycling in the range from $-0.7 \mathrm{~V}$ to $2 \mathrm{~V}$ at $\mathrm{AD}$-DLC and from $-0.7 \mathrm{~V}$ to $2.6 \mathrm{~V}$ at O-DLC. The CVs of $5 \mathrm{mM} 2,4-\mathrm{DCP}$ at 1 st and 5th cycles were shown in Figure 7. At both electrode surfaces, the peak current disappeared by fifth cycles, and the fouling occurred because polymeric films were formed on the electrode surface. However, when the fouled AD-DLC and O-DLC electrodes were treated anodically in the BrittonRobinson buffer solution at $2.64 \mathrm{~V}$ versus $\mathrm{Ag} / \mathrm{AgCl}$ for 4 minutes, the peak current densities could recover to the same levels of the initial values, as shown in Figures 7(c) and 7(d) [29]. The passive layer on DLC was thought to be completely oxidized (decomposed), and the reaction products were thought to be removed from the oxidized DLC surface. The similar recovery by anodic treatment after the potential cycling in higher concentration 2,4-DCP was observed at $\mathrm{BDD}$ (Figure $7(\mathrm{~b})$ ). The results at BDD were similar to the results in the literature [29]. In the process of the complete oxidation of the passive layer on BDD, hydroxyl radicals generated on the BDD surface at higher potential region $(>1.6 \mathrm{~V})$ have been reported to play an important role [29]. The complete recovery of the peak current at DLC suggests the production of hydroxyl radicals at DLC in higher potential range and the decomposition of passive layer by $\mathrm{OH}$ radicals. In separate experiment (not shown), $\mathrm{OH}$ radicals related to electrogenerated chemiluminescence reaction in the system of $\mathrm{Ru}(\mathrm{bpy})^{3+}$ with ascorbic acid could be observed in the potential over $2.0 \mathrm{~V}$ at O-DLC. This 


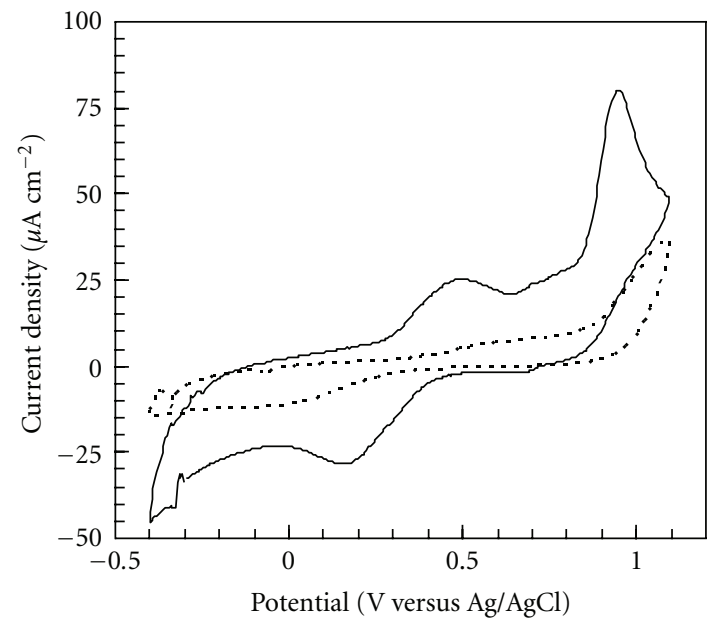

(a) GC

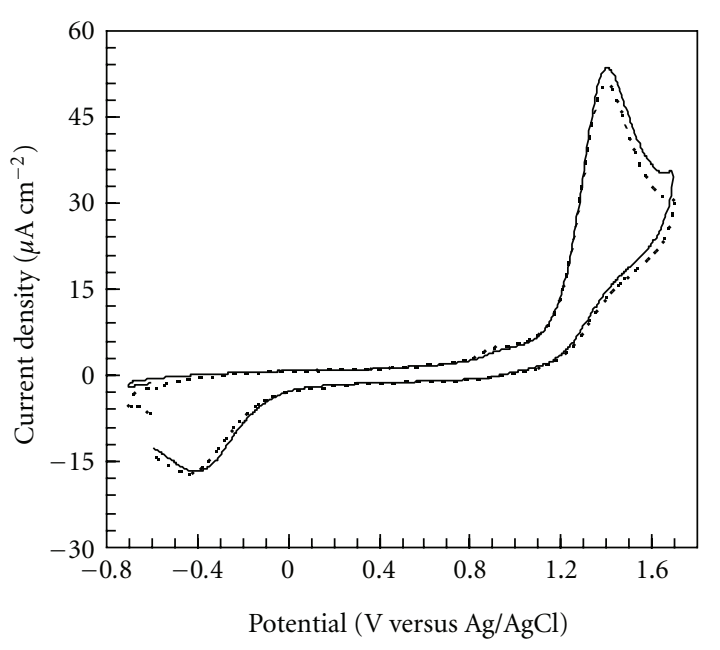

(c) O-BDD

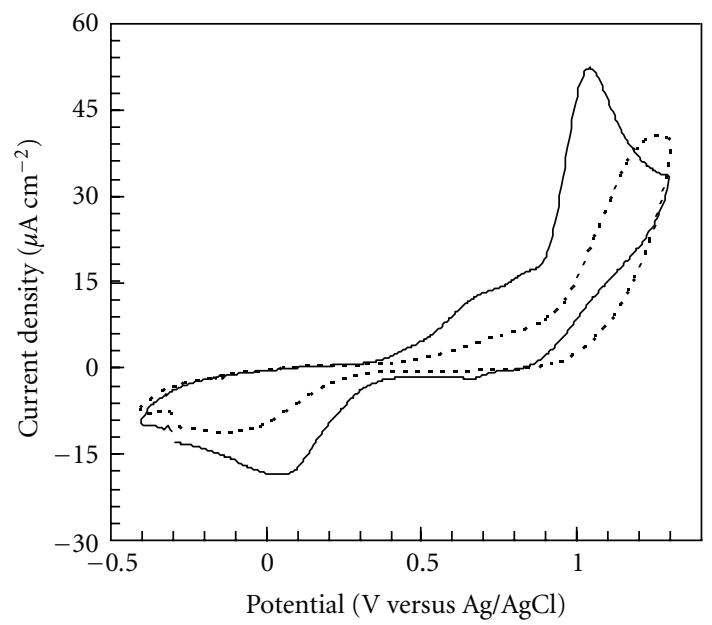

(b) H-BDD

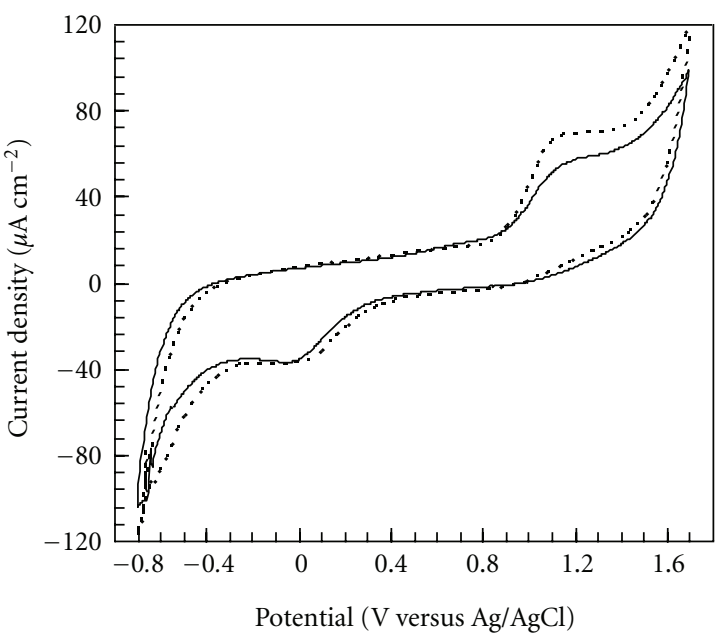

(d) AD-DLC

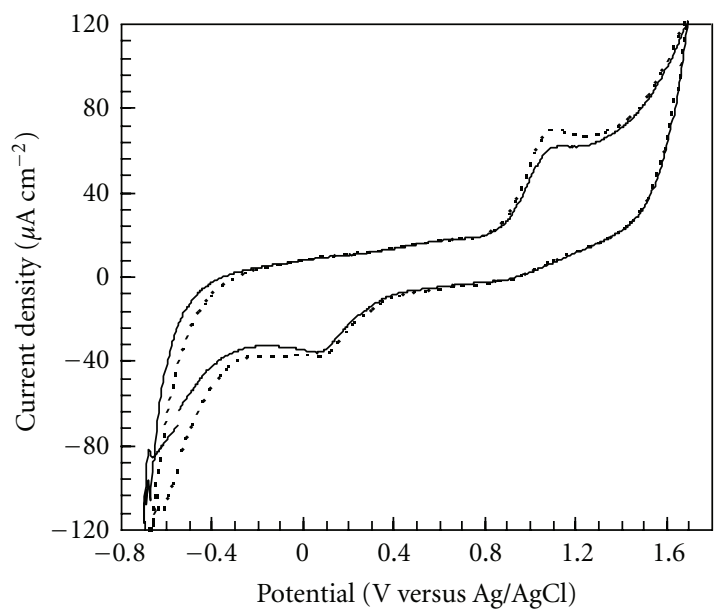

(e) O-DLC

Figure 5: Cyclic voltammograms of $0.1 \mathrm{mM}$ 2,4-DCP in the Britton-Robinson buffer (pH 2) at (a) GC, (b) H-BDD, (c) O-BDD, (d) ADDLC, and (e) O-DLC at initial (solid line) and 30 cycles (dotted line). Sweep rate, $100 \mathrm{mV} \mathrm{s}^{-1}$. 


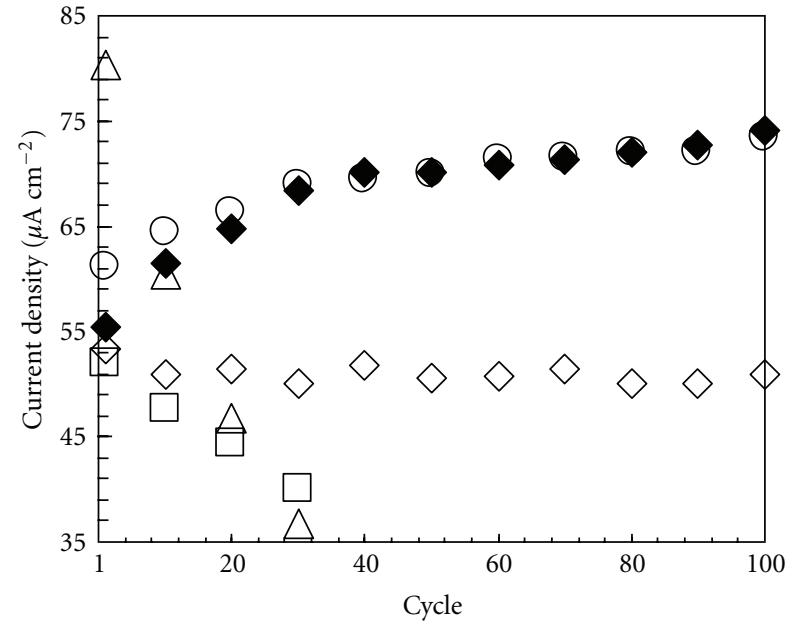

Figure 6: Relationship of the number of the potential cycling and the anodic peak current density in cyclic voltammograms of $0.1 \mathrm{mM}$ 2,4-dichlorophenol in the Britton-Robinson buffer ( $\mathrm{pH}$ 2) at $(\diamond)$ AD-DLC, $(\bigcirc)$ O-DLC, $(\square)$ H-BDD, $(\diamond) \mathrm{O}-\mathrm{BDD}$, and $(\triangle)$ GC.

observation indicates that $\mathrm{OH}$ radicals are available on the DLC surface at higher potential region [30]. At GC, the ratio of the recovered peak current density after anodic treatment to the initial values was relatively lower (0.7) than DLC, and the background current was remarkably increased after surface oxidation (Figure 7(a)).

It can be summarized that DLC exhibits an excellent stability of the electrochemical reaction response for innersphere redox species that induce an inevitable fouling of the electrode surface although molecules with polarity are highly adsorbed on the DLC surface. Higher stability at DLC is caused by the production of $\mathrm{OH}$ radicals and the negative surface dipolar field on the O-DLC surface. These surface properties were similar to those for BDD.

\subsubsection{Selective Electrochemical Detection of Dopamine in the} Presence of Uric Acid. While the DLC surface exhibited substantial shift in negative direction of oxidation peak potential for positively charged inner sphere redox species by surface oxidation, the peak potential of the neutral redox compounds at DLC did not vary before and after oxidative treatment. This feature of the oxidized DLC surface makes it possible to discriminate between the dopamine (DA; positively charged) and uric acid (UA; no charge) responses.

In $\mathrm{CV}$ of the solution containing single redox analyte at AD-DLC (Figure $8(\mathrm{a})$ ), the peak potential of DA $(50 \mu \mathrm{M})$ oxidation was obtained at $0.77 \mathrm{~V}$, and that of UA $(50 \mu \mathrm{M})$ weas observed at $0.90 \mathrm{~V}$. After oxygen plasma treatment, the peak potential of UA oxidation (in single analyte solution) was observed at $0.88 \mathrm{~V}$ with a shift only $-20 \mathrm{mV}$ from the peak potential at AD-DLC (Figure 8(b)). In contrast, for DA oxidation at O-DLC, the peak potential was $0.70 \mathrm{~V}$ (Figure $8(\mathrm{~b}))$. The value was shifted by approximately
$-70 \mathrm{mV}$ from that at the untreated DLC. As a result, by oxidative treatment, the difference between UA and DA peak potentials was increased from $0.13 \mathrm{~V}$ to $0.18 \mathrm{~V}$. Cyclic voltammogram of the electrolyte including two-analyte $50 \mu \mathrm{M}$ DA and $50 \mu \mathrm{M}$ UA at the AD-DLC surface is shown in Figure $8(\mathrm{a})$. The oxidation peaks for DA and UA were observed at $0.78 \mathrm{~V}$ and $0.90 \mathrm{~V}$, respectively. The peak for DA oxidation was not well defined and observed as a shoulder of UA oxidation peak. The peak current densities for DA oxidation showed a linear relation with DA concentration in a range from $5 \mu \mathrm{M}$ to $100 \mu \mathrm{M}$ in the presence of $50 \mu \mathrm{M} \mathrm{UA}$, and the theoretical detection limit of DA detection at $\mathrm{AD}$ DLC was estimated to be $280 \mathrm{nM}(\mathrm{S} / \mathrm{N}=3)$.

The cyclic voltammogram obtained at the O-DLC electrode for the solution containing both $50 \mu \mathrm{M}$ DA and $50 \mu \mathrm{M}$ UA is shown in Figure 8(b). Two well-defined anodic peaks attributable to DA and UA oxidation were observed at $0.70 \mathrm{~V}$ and $0.88 \mathrm{~V}$, respectively, and two peaks were clearly separated. The linear relation between the peak current densities and DA concentration was observed in the range from $1 \mu \mathrm{M}$ to $250 \mu \mathrm{M}$ in the presence of $50 \mu \mathrm{M}$ UA at the O-DLC surface. The theoretical detection limit was calculated to be $58 \mathrm{nM}$ $(\mathrm{S} / \mathrm{N}=3)$. From these results, it can be concluded that $\mathrm{O}$ DLC allows the selective and highly sensitive ( 5 times higher) detection of DA compared with AD-DLC from the mixed solution of DA and UA.

At the H-BDD electrode, the oxidation peaks of $50 \mu \mathrm{M}$ DA and UA in each solution containing single analyte were observed at $0.77 \mathrm{~V}$ and $0.85 \mathrm{~V}$, respectively (Figure $8(\mathrm{c})$ ). On the oxidized BDD surface, the peak potentials of DA and UA oxidation (in single analyte solution) were positively shifted (the peak potential was 0.96 and $0.99 \mathrm{~V}$, resp.). The potential difference was indifferent to the surface condition of BDD. Consequently, voltammograms of a solution containing both $50 \mu \mathrm{M}$ DA and $50 \mu \mathrm{M}$ UA obtained at both H-BDD and O-BDD (Figures 8(c) and 8(d)) surfaces exhibited a single broad peak. It indicates that BDD could not discriminate DA from the mixed solution of DA and UA.

From these results, by using O-DLC, the kinetics of the positively charged inner-sphere redox species at DLC can be improved by oxidative treatment, the selective detection of the inner-sphere redox species with positive charge such as DA from the mixed media can be realized, which is impossible at BDD. The negative shifts of the oxidation peak potential of inner-sphere redox species (such as DA) at ODLC can contribute the improvement of the low detection limits by ca. one order of magnitude.

\section{Conclusions}

Nitrogen-doped hydrogenated amorphous carbon thin films that have a N/C ratio of 0.08 and contain $s p^{3}$-bonded carbons with atomic ratio $22 / 78 s p^{3} / s p^{2}$ were synthesized with microwave-assisted plasma-enhanced CVD chemical vapor deposition method. To fabricate the electrode interface with higher electrochemical reactivity and higher stability, the surface were modified by oxygen plasma treatment, and 


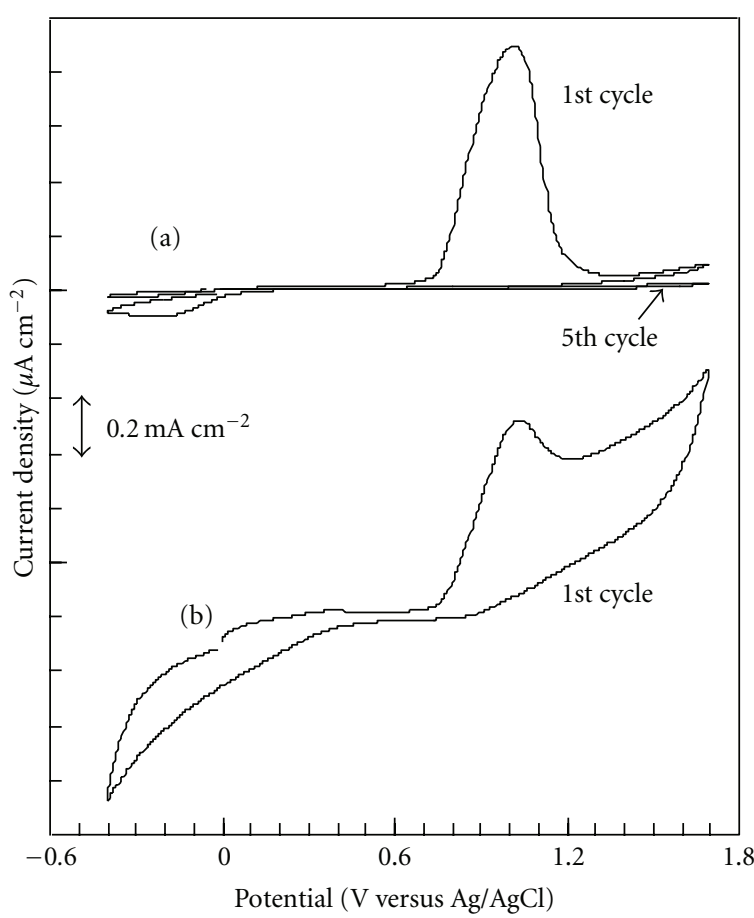

(a) GC

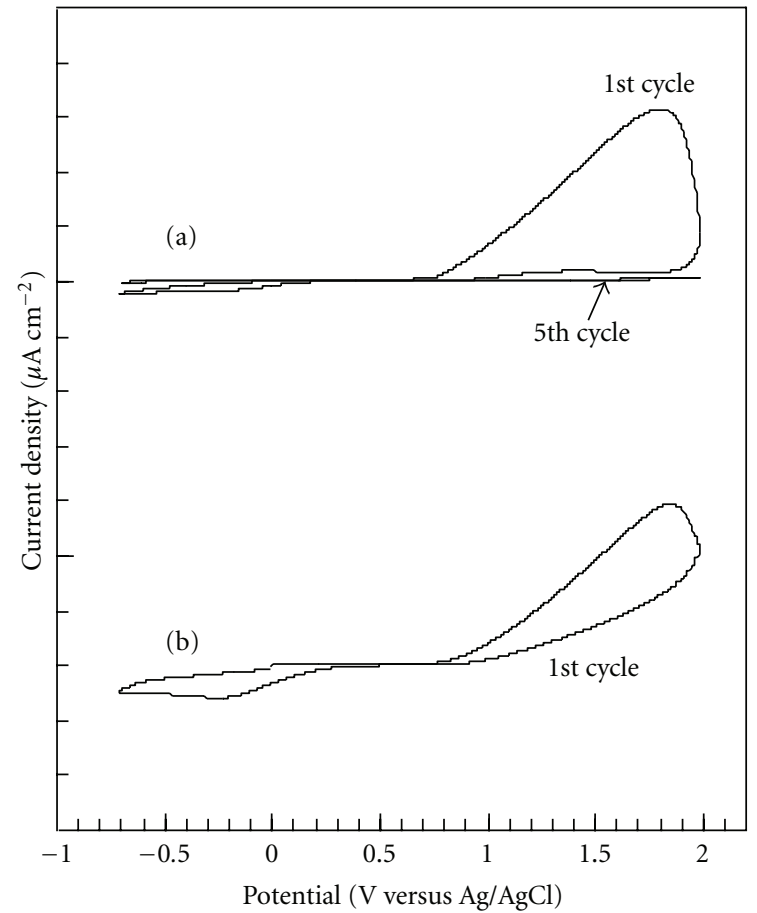

(c) AD-DLC

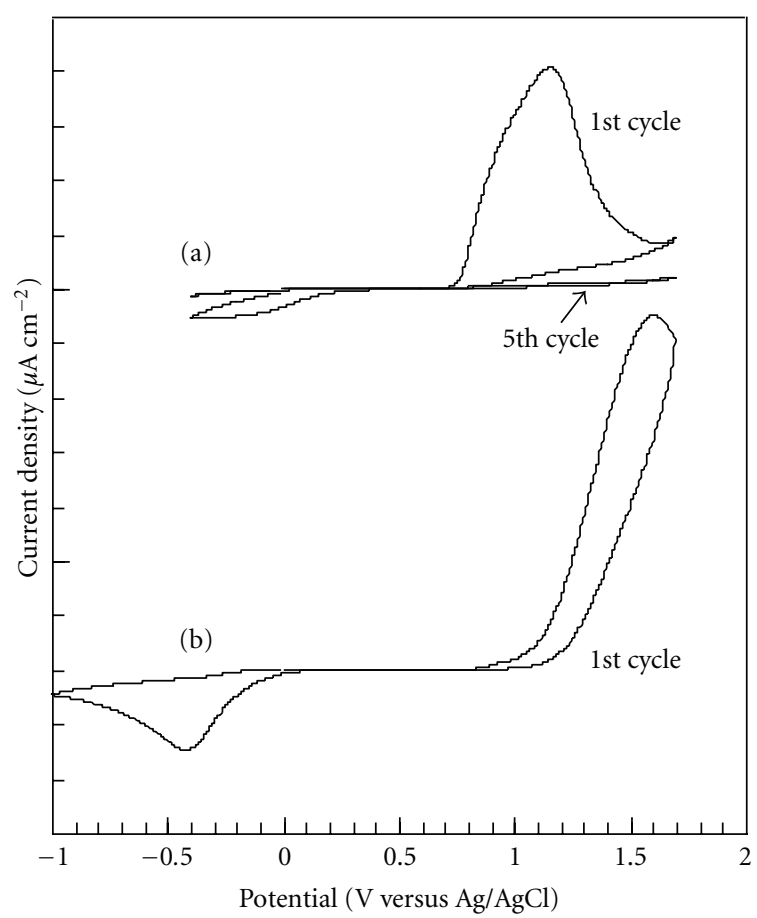

(b) H-BDD

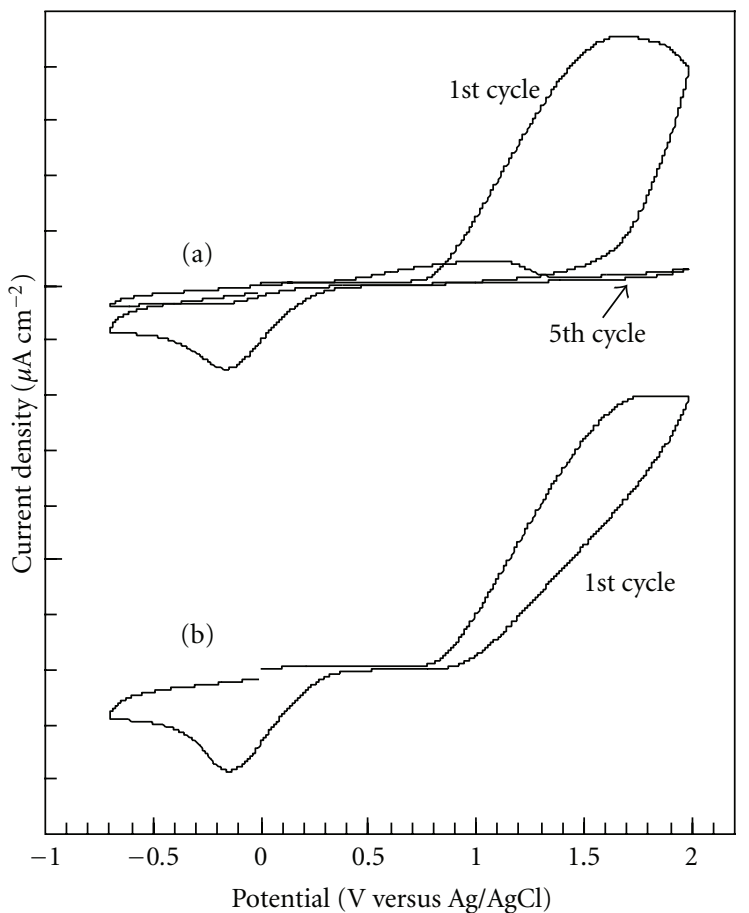

(d) O-DLC

Figure 7: Cyclic voltammograms of $5 \mathrm{mM}$ 2,4-DCP in the Britton-Robinson buffer (pH 2) at (a) GC, (b) H-BDD, (c) AD-DLC, and (d) O-DLC at initial (solid line) and 30 cycles (dotted line) (a) before and (b) after the electrochemical treatment at $2.64 \mathrm{~V}$ for 4 min. Sweep rate, $100 \mathrm{mV} \mathrm{s}^{-1}$.

the performance and the durability of the oxidized N-doped DLC surface toward electrochemical reaction werevaluated.

The N-doped DLC thin films exhibited a wide working potential range over $3 \mathrm{~V}$, low double-layer capacitance, and reversible electron transfer kinetics for inorganic redox analytes, $\left[\mathrm{Fe}(\mathrm{CN})_{6}\right]^{3-/ 4-}, \mathrm{Ru}\left(\mathrm{NH}_{3}\right)_{6}^{2+/ 3+}$, and $\mathrm{Fe}^{2+/ 3+}$, which were on the same level as those of BDD.

The electrochemical activity toward the inner-sphere redox species is controllable by modifying the N-DLC surface because N-DLC includes the $s p^{2}$ carbons. At the 


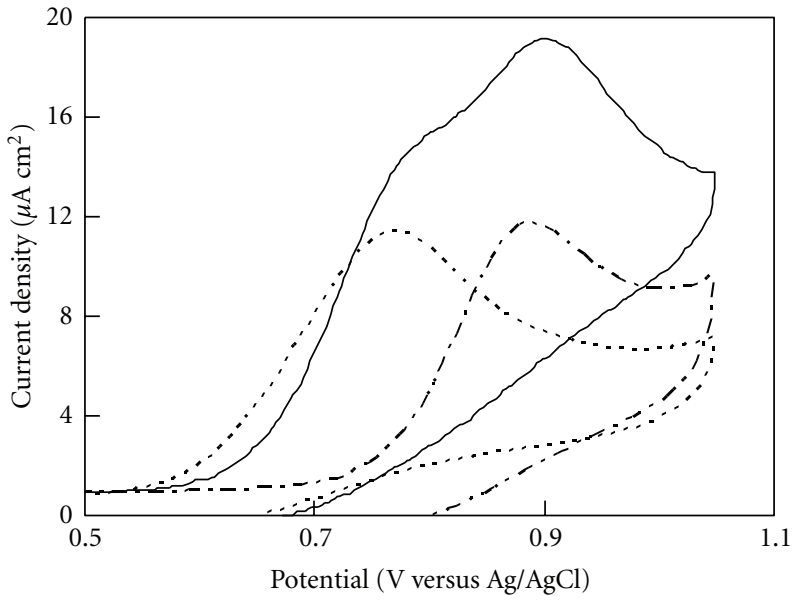

(a)

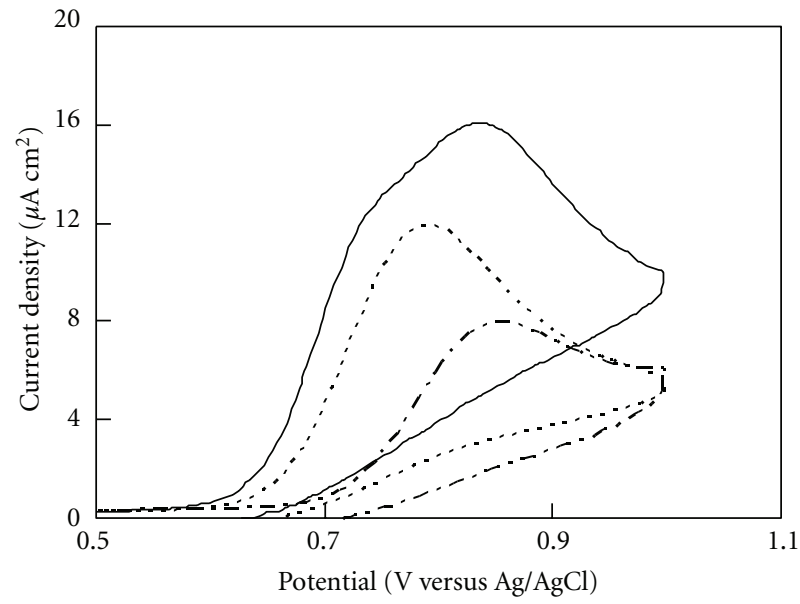

(c)

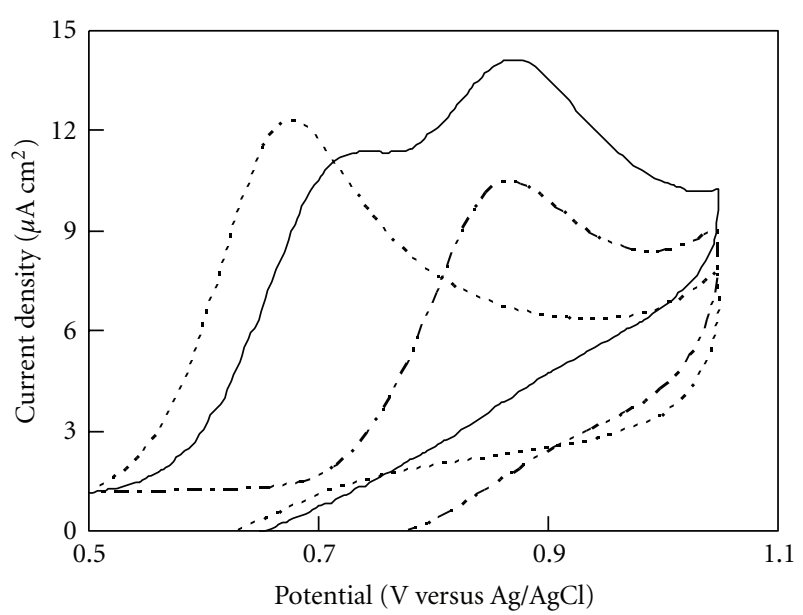

(b)

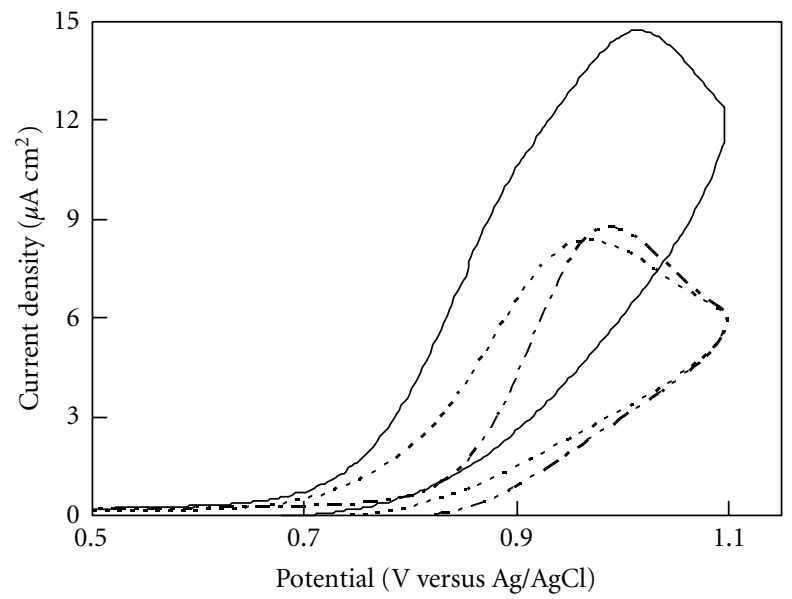

(d)

Figure 8: Cyclic voltammograms of a solution containing $50 \mu \mathrm{M}$ dopamine hydrochloride $+50 \mu \mathrm{M}$ uric acid (solid line), $50 \mu \mathrm{M}$ dopamine (dotted line) and $50 \mu \mathrm{M}$ uric acid (dashed-dotted line) at (a) AD-DLC, (b) O-DLC, (c) H-BDD, and (d) O-BDD. Sweep rate, $20 \mathrm{mV} \mathrm{s}^{-1}$.

oxygen-plasma-treated DLC surface, the surface functional groups including carbon doubly bonded to oxygen $(\mathrm{C}=\mathrm{O})$, which improves adsorption of polar molecules, were generated. By this effect, the electron-transfer rate for dopamine, positively charged inner-sphere redox analyte, was improved.

Besides, the AD-DLC and the O-DLC surfaces exhibited remarkably higher stability and reproducibility of the electrode performance, which are close to BDD, for redox reaction of 2,4-DCP which is electrochemically active species and induces the inevitable fouling on the anode surface. These unique electrochemical characteristics of the oxidized surface of DLC make it possible to discriminate between the oxidation peaks of DA and UA in an amperometric measurement for the mixed solution of DA and UA, which was hard at BDD.

Hence, N-doped DLC is a promising ideal polarizable electrode material with higher reactivity and high stability toward inner-sphere redox system and higher physical stability and chemical inertness, alternative to BDD in the future. However, in order to realize the electrochemical applications using N-doped DLC, there are some problems that should be dealt with. One of them is the higher resistivity of N-doped DLC films.

For example, further functionalities are expected if the comb-like structure can be fabricated using free-standing $\mathrm{N}$-doped DLC thin films. The carrier density of N-doped DLC deposited in this study was not so high. The volume resistivity was approximately three orders of magnitude higher than that of heavily boron-doped diamond. In order to apply the self-standing DLC film in $\mu \mathrm{m}$ order thickness as an electrode with comb-like structures, it is required to reduce the volume resistivity by ca. two orders of magnitude. If the volume resistivity is reduced, N-doped DLC can be applied in a wide range for sure.

\section{References}

[1] J. Xu, M. C. Granger, Q. Chen, J. W. Strojek, T. E. Lister, and G. M. Swain, "Boron-doped diamond thin-film electrodes," Analytical Chemistry, vol. 69, no. 19, 1997. 
[2] R. Tenne and C. Lévy-Clément, "Diamond electrodes," Israel Journal of Chemistry, vol. 38, no. 1-2, pp. 57-73, 1998.

[3] K. Yoo, B. Miller, R. Kalish, and X. Shi, "Electrodes of nitrogenincorporated tetrahedral amorphous carbon. A novel thinfilm electrocatalytic material with diamond-like stability," Electrochemical and Solid-State Letters, vol. 2, no. 5, pp. 233 235, 1999.

[4] K. Yoo, B. Miller, X. Shi, and R. Kalish, "Copper electrodeposition and dissolution on tetrahedral amorphous carbon incorporating nitrogen," Journal of the Electrochemical Society, vol. 148, no. 2, pp. C95-C101, 2001.

[5] D. Sopchak, B. Miller, R. Kalish, Y. Avyigal, and X. Shi, "Dopamine and ascorbate analysis at hydrodynamic electrodes of boron doped diamond and nitrogen incorporated tetrahedral amorphous carbon," Electroanalysis, vol. 14, no. 78, pp. 473-478, 2002.

[6] N. C. Yee, Q. Shi, W. B. Cai, D. A. Scherson, and B. Miller, "Electrochemical characterization of nitrogen-incorporated tetrahedral carbon films grown by a filtered cathodic vacuum arc," Electrochemical and Solid-State Letters, vol. 4, no. 10, pp. E42-E44, 2001.

[7] A. Zeng, M. M. M. Bilek, D. R. McKenzie, and P. A. Lay, "Correlation of film structure and molecular oxygen reduction at nitrogen doped amorphous carbon thin film electrochemical electrodes," Diamond and Related Materials, vol. 18, no. 9, pp. 1102-1108, 2009.

[8] A. Zeng, M. M. M. Bilek, D. R. McKenzie, and P. A. Lay, "Semiconductor properties and redox responses at a-C:N thin film electrochemical electrodes," Diamond and Related Materials, vol. 18, no. 10, pp. 1211-1217, 2009.

[9] A. Lagrini, C. Deslouis, H. Cachet, M. Benlahsen, and S. Charvet, "Elaboration and electrochemical characterization of nitrogenated amorphous carbon films," Electrochemistry Communications, vol. 6, no. 3, pp. 245-248, 2004.

[10] P. Tamiasso-Martinhon, H. Cachet, C. Debiemme-Chouvy, and C. Deslouis, "Thin films of amorphous nitrogenated carbon a-CNx: electron transfer and surface reactivity," Electrochimica Acta, vol. 53, no. 19, pp. 5752-5759, 2008.

[11] Y. V. Pleskov, M. D. Krotova, V. I. Polyakov et al., "Electrochemical behaviour of a-C:N:H films," Journal of Electroanalytical Chemistry, vol. 519, no. 1-2, pp. 60-64, 2002.

[12] Y. Tanaka, M. Furuta, K. Kuriyama et al., "Electrochemical properties of $\mathrm{N}$-doped hydrogenated amorphous carbon films fabricated by plasma-enhanced chemical vapor deposition methods," Electrochimica Acta, vol. 56, no. 3, pp. 1172-1181, 2011.

[13] P. Wood, T. Wydeven, and O. Tsuji, "Influence of reactant gas composition on selected properties of N-doped hydrogenated amorphous carbon films," Thin Solid Films, vol. 258, no. 1-2, pp. 151-158, 1995.

[14] L. Boonma, T. Yano, D. A. Tryk, K. Hashimoto, and A. Fujishima, "Observation of photocurrent from band-to-band excitation of semiconducting p-type diamond thin film electrodes," Journal of the Electrochemical Society, vol. 144, no. 6, pp. L142-L145, 1997.

[15] A. C. Ferrari and J. Robertson, "Interpretation of Raman spectra of disordered and amorphous carbon," Physical Review $B$, vol. 61, no. 20, pp. 14095-14107, 2000.

[16] C. Casiraghi, A. C. Ferrari, and J. Robertson, "Raman spectroscopy of hydrogenated amorphous carbons," Physical Review B, vol. 72, no. 8, Article ID 085401, 14 pages, 2005.

[17] G. Adamopoulos, K. W. R. Gilkes, J. Robertson et al., "Ultraviolet Raman characterisation of diamond-like carbon films," Diamond and Related Materials, vol. 8, no. 2-5, pp. 541-544, 1999.

[18] A. C. Ferrari and J. Robertson, "Raman spectroscopy of amorphous, nanostructured, diamond-like carbon, and nanodiamond," Philosophical Transactions of the Royal Society A, vol. 362, no. 1824, pp. 2477-2512, 2004.

[19] T. Kondo, H. Ito, K. Kusakabe et al., "Plasma etching treatment for surface modification of boron-doped diamond electrodes," Electrochimica Acta, vol. 52, no. 11, pp. 3841-3848, 2007.

[20] H. B. Martin, A. Argoitia, U. Landau, A. B. Anderson, and J. C. Angus, "Hydrogen and oxygen evolution on boron-doped diamond electrodes," Journal of the Electrochemical Society, vol. 143, no. 6, pp. L133-L136, 1996.

[21] I. Yagi, H. Notsu, T. Kondo, D. A. Tryk, and A. Fujishima, "Electrochemical selectivity for redox systems at oxygenterminated diamond electrodes," Journal of Electroanalytical Chemistry, vol. 473, no. 1, pp. 173-178, 1999.

[22] P. Chen and R. L. McCreery, "Control of electron transfer kinetics at glassy carbon electrodes by specific surface modification," Analytical Chemistry, vol. 68, no. 22, pp. 3958-3965, 1996.

[23] M. C. Granger, M. Witek, J. Xu et al., "Standard electrochemical behavior of high-quality, boron-doped polycrystalline diamond thin-film electrodes," Analytical Chemistry, vol. 72, no. 16, pp. 3793-3804, 2000.

[24] J. Xu, Q. Chen, and G. M. Swain, "Anthraquinonedisulfonate electrochemistry: a comparison of glassy carbon, hydrogenated glassy carbon, highly oriented pyrolytic graphite, and diamond electrodes," Analytical Chemistry, vol. 70, no. 15, pp. 3146-3154, 1998.

[25] Q. Chen and G. M. Swain, "Structural characterization, electrochemical reactivity, and response stability of hydrogenated glassy carbon electrodes," Langmuir, vol. 14, no. 24, pp. 70177026, 1998.

[26] Y. Show, M. A. Witek, P. Sonthalia, and G. M. Swain, "Characterization and electrochemical responsiveness of boron-doped nanocrystalline diamond thin-film electrodes," Chemistry of Materials, vol. 15, no. 4, pp. 879-888, 2003.

[27] E. Popa, H. Notsu, T. Miwa, D. A. Tryk, and A. Fujishima, "Selective electrochemical detection of dopamine in the presence of ascorbic acid at anodized diamond thin film electrodes," Electrochemical and Solid-State Letters, vol. 2, no. 1, pp. 49-51, 1999.

[28] D. A. Tryk, H. Tachibana, H. Inoue, and A. Fujishima, "Borondoped diamond electrodes: the role of surface termination in the oxidation of dopamine and ascorbic acid," Diamond and Related Materials, vol. 16, no. 4-7, pp. 881-887, 2007.

[29] C. Terashima, T. N. Rao, B. V. Sarada, D. A. Tryk, and A. Fujishima, "Electrochemical oxidation of chlorophenols at a boron-doped diamond electrode and their determination by high-performance liquid chromatography with amperometric detection," Analytical Chemistry, vol. 74, no. 4, pp. 895-902, 2002.

[30] K. Honda, Y. Yamaguchi, Y. Yamanaka, M. Yoshimatsu, Y. Fukuda, and A. Fujishima, "Hydroxyl radical-related electrogenerated chemiluminescence reaction for a ruthenium tris $\left(2,2^{\prime}\right)$ bipyridyl/co-reactants system at boron-doped diamond electrodes," Electrochimica Acta, vol. 51, no. 4, pp. 588597, 2005. 


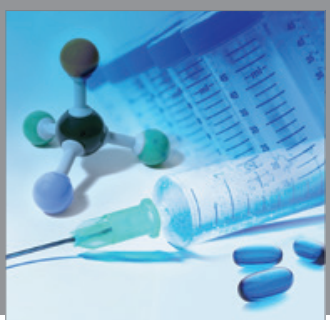

International Journal of

Medicinal Chemistry

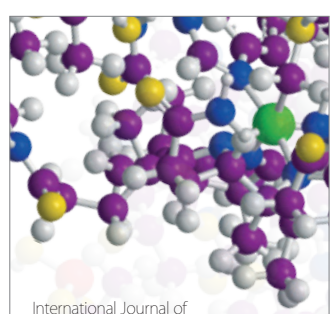

Carbohydrate Chemistry

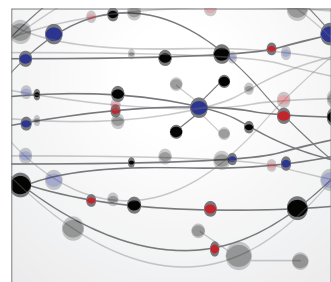

The Scientific World Journal
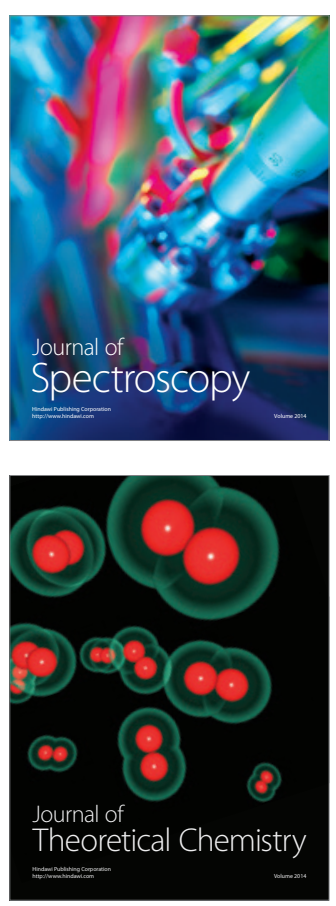
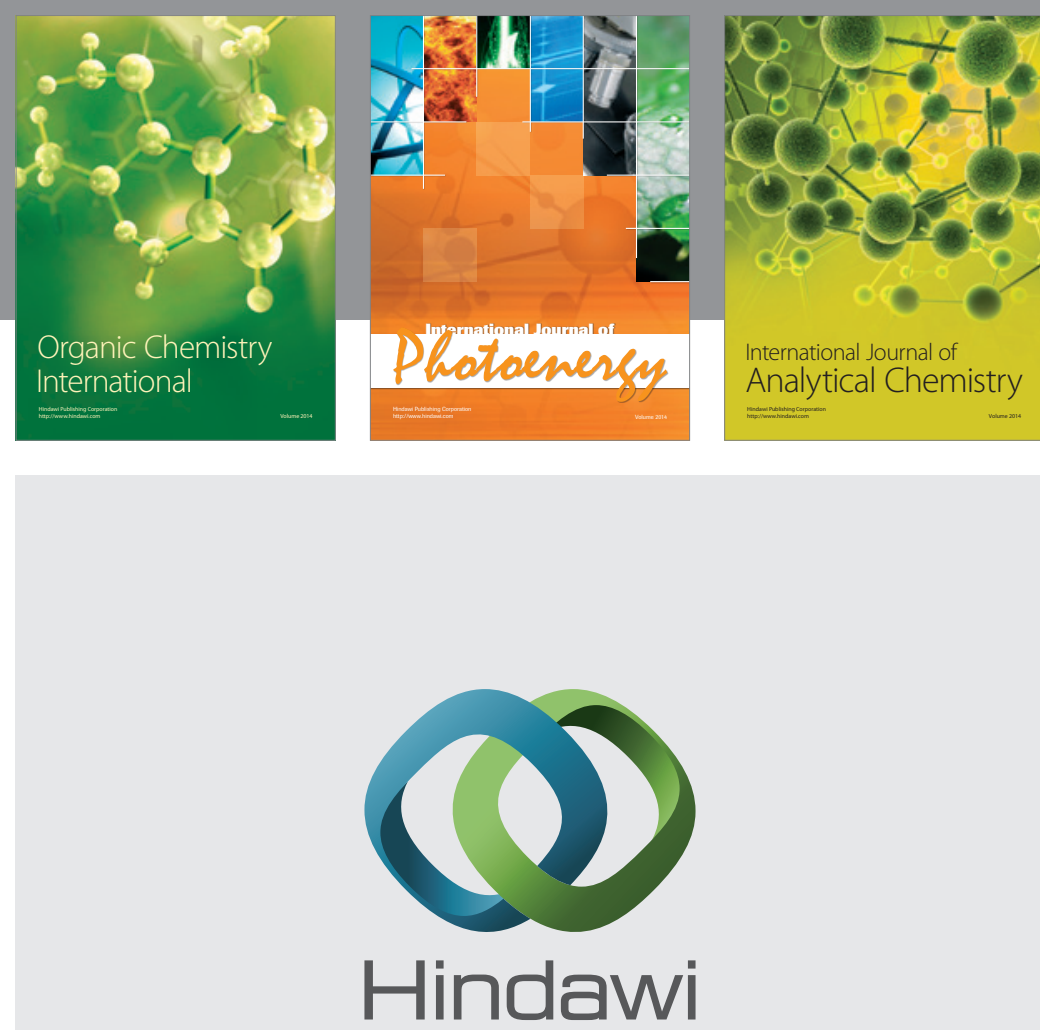

Submit your manuscripts at

http://www.hindawi.com
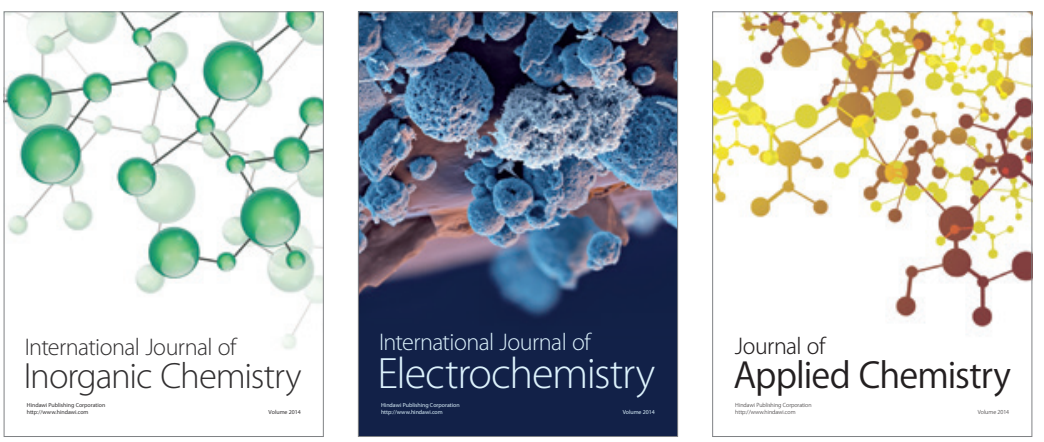

Journal of

Applied Chemistry
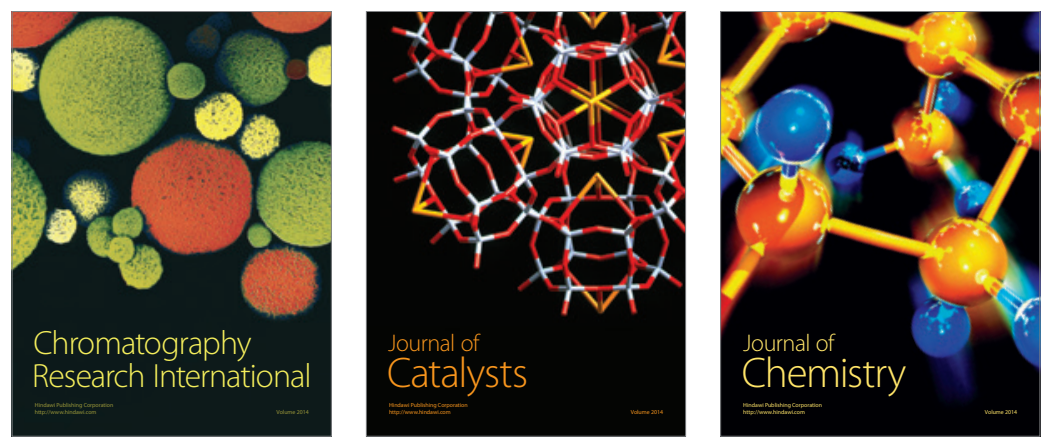
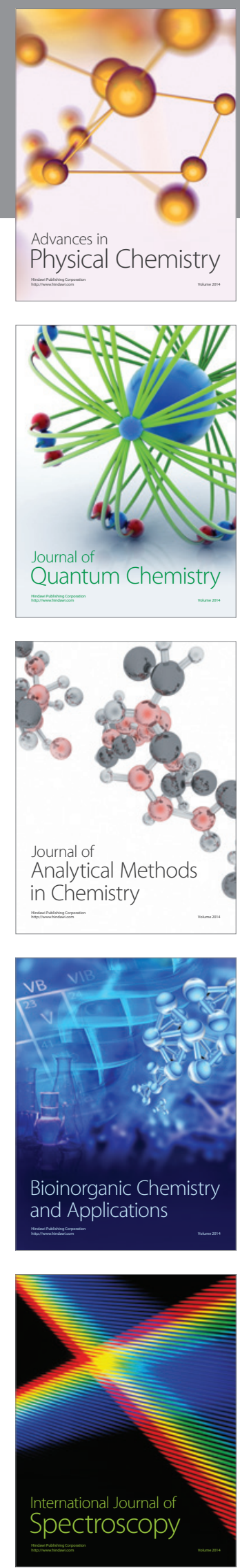